The Texas Medical Center Library

DigitalCommons@TMC

The University of Texas MD Anderson Cancer Center UTHealth Graduate School of

Biomedical Sciences Dissertations and Theses

(Open Access)
The University of Texas MD Anderson Cancer

Center UTHealth Graduate School of

Biomedical Sciences

$5-2010$

\title{
Influence of Anchoring on Miscarriage Risk Perception Associated with Amniocentesis
}

\author{
Regina A. Nuccio
}

Follow this and additional works at: https://digitalcommons.library.tmc.edu/utgsbs_dissertations

Part of the Diagnosis Commons

\section{Recommended Citation}

Nuccio, Regina A., "Influence of Anchoring on Miscarriage Risk Perception Associated with Amniocentesis" (2010). The University of Texas MD Anderson Cancer Center UTHealth Graduate School of Biomedical Sciences Dissertations and Theses (Open Access). 49.

https://digitalcommons.library.tmc.edu/utgsbs_dissertations/49

This Thesis (MS) is brought to you for free and open access by the The University of Texas MD Anderson Cancer Center UTHealth Graduate School of Biomedical Sciences at DigitalCommons@TMC. It has been accepted for inclusion in The University of Texas MD Anderson Cancer Center UTHealth Graduate School of Biomedical Sciences Dissertations and Theses (Open Access) by an authorized administrator of DigitalCommons@TMC. For more information, please contact digitalcommons@library.tmc.edu.

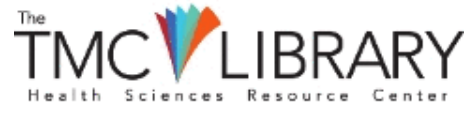




\section{WITH AMNIOCENTESIS}

by

\section{Regina Nuccio, BS}

APPROVED:
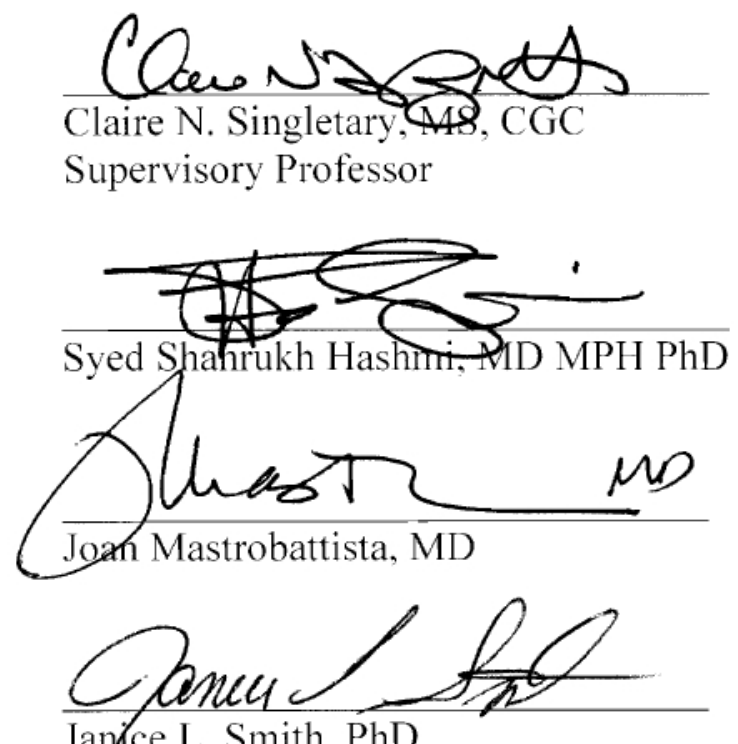

Janice L. Smith, PhD
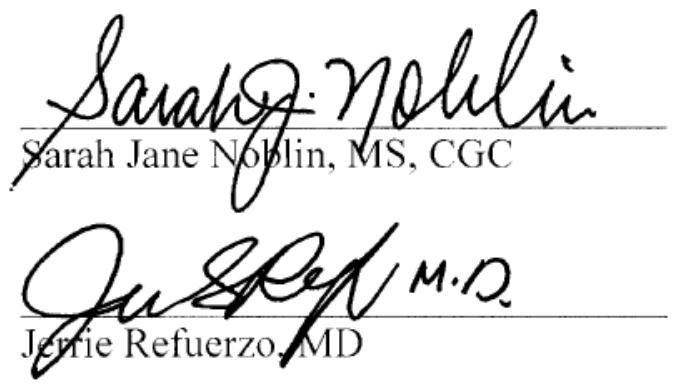

\section{APPROVED:}

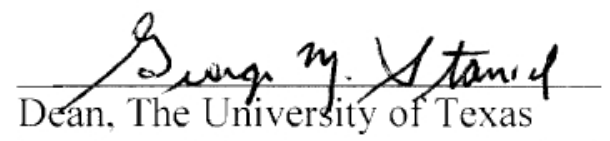

Graduate School of Biomedical Sciences at Houston 


\title{
INFLUENCE OF ANCHORING ON MISCARRIAGE RISK PERCEPTION ASSOCIATED WITH AMNIOCENTESIS
}

\author{
A \\ THESIS \\ Presented to the Faculty of \\ The University of Texas \\ Health Science Center at Houston \\ and \\ The University of Texas \\ M. D. Anderson Cancer Center \\ Graduate School of Biomedical Sciences \\ in Partial Fulfillment of the Requirements \\ for the Degree of \\ MASTER OF SCIENCE \\ by
}

Regina Nuccio, BS

Houston, Texas

May 2010 


\section{ACKNOWLEDGEMENTS}

I wish to express my deepest gratitude to my advisory committee for their invaluable guidance and support throughout the development of this project. Claire N. Singletary, Dr. Joan Mastrobattista, Dr. Jerrie Refuerzo, Dr. Jan Smith, Dr. Syed Hashmi, and Sarah Jane Noblin - I am appreciative to each of you for your advice that allowed the project to come to fruition. I would especially like to thank Claire Singletary, my thesis chair, for her immense guidance, patience, and support throughout the entire project. Claire has also served as a mentor, teacher, and confidant throughout my two years in the genetic counselor program. I simply cannot express the gratitude I have for Claire. My life has been made better by her guidance.

I also wish to acknowledge the supervisors, faculty, and staff of the University of Texas Genetic Counseling Program. It has been evident to me in the past two years that everyone involved in the training program has a deep love for guiding students and aiding them in becoming the best genetic counselors that they can. My classmates have also given me steady support throughout this process for which I am deeply grateful.

I would finally like to thank countless family and friends who have supported me in this journey. My parents have supported me both financially and emotionally for my entire life. Without their provision, my dream of becoming a genetic counselor would not have been made reality. And finally, I would like to thank David for his unwavering encouragement. 


\title{
INFLUENCE OF ANCHORING ON MISCARRIAGE RISK PERCEPTION ASSOCIATED WITH AMNIOCENTESIS
}

\author{
Publication No. \\ Regina Nuccio, BS \\ Supervisory Professor: Claire N. Singletary, MS, CGC
}

Amniocentesis is the most common invasive procedure performed during pregnancy (Eddleman, et al., 2006). One important factor that women consider when making a decision about amniocentesis is the risk of miscarriage associated with the procedure. People use heuristics such as anchoring, the action of using a prior belief regarding the magnitude of risk as a frame of reference for new information to be synthesized, to better understand risks that they encounter in their lives. This study aimed to determine a woman's perception of miscarriage risk associated with amniocentesis before and after a genetic counseling session and to determine what factors are most likely to anchor a woman's perception of miscarriage risk associated with amniocentesis. Most women perceived the risk as low or average precounseling and were likely to indicate the numeric risk of amniocentesis as $<1 \%$ risk. A higher percentage of patients correctly identified the numeric risk as $<1 \%$ post-counseling when compared to pre-counseling. However, the majority of patients' feeling about the risk perception did not change after the genetic counseling session (60\%), regardless of how they perceived the risk before discussing amniocentesis with a genetic counselor. Those whose risk perception did change after discussing amniocentesis with a genetic counselor showed a decreased risk perception $(\mathrm{p}<0.0001)$. Of the multitude of factors studied, only two showed significance: having a friend or relative with a personal or family history of a genetic disorder was associated with a lower risk perception $(\mathrm{p}=0.001)$ and having a child already 
was associated with a lower risk perception $(\mathrm{p}=0.038)$. The lack of significant factors may reflect the uniqueness of each patient's heuristic framework and reinforces the importance of genetic counseling to elucidate individual concerns. 


\section{TABLE OF CONTENTS}

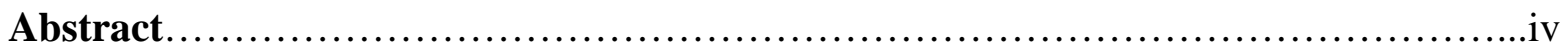

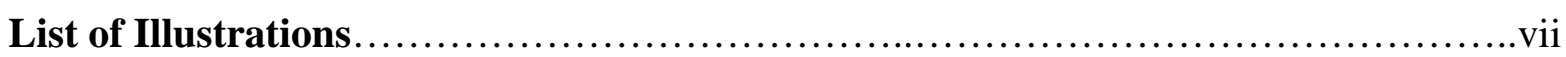

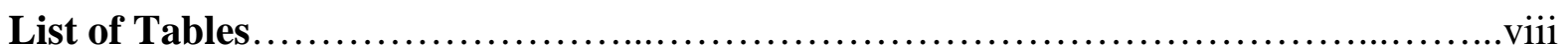

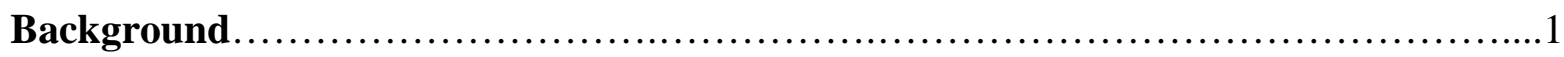

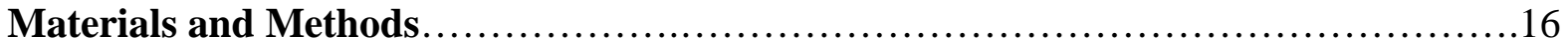

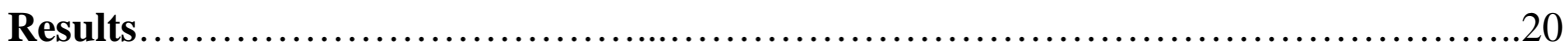

Discussion.................................................................. 52

Appendices

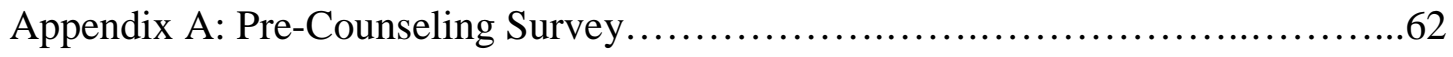

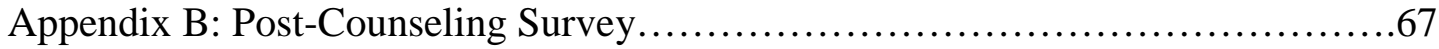

Appendix C: Genetic Counseling Survey..................................68

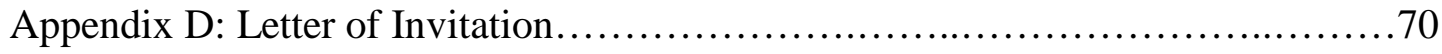

References...................................................................... 72






\section{LIST OF ILLUSTRATIONS}

Figure 1. Miscarriage Risk Quantification Before Counseling (Percentage Form)..........26

Figure 2. Perception of Miscarriage Risk Before Counseling.........................27

Figure 3. Miscarriage Risk Quantification After Counseling (Percentage Form).............38

Figure 4. Comparison of Miscarriage Risk Quantification Before and After Counseling

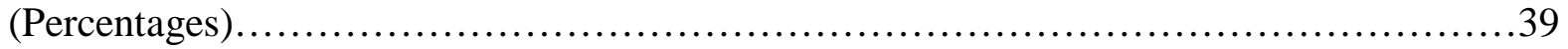

Figure 5. Perception of Miscarriage Risk After Counseling............................40

Figure 6. Change in Risk Perception...........................................45

Figure 7. Degree of Change in Risk Perception Before and After Counseling..............46 


\section{LIST OF TABLES}

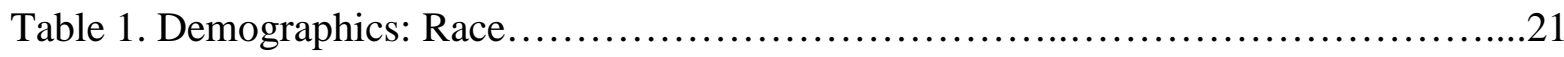

Table 2. Demographics: Education................................................ 21

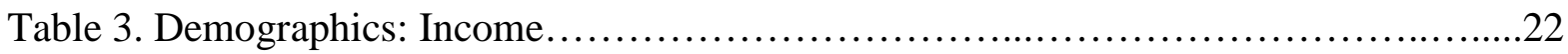

Table 4a. Demographics: Religion............................................... 22

Table 4b: Demographics: Religion Revised.......................................23

Table 5. Numeric Risk Before Counseling.......................................24

Table 6. Percentage Risk Before Counseling....................................25

Table 7. Comparison of Miscarriage Risk Perception Before Counseling and Patient

Discussions with Various Individuals..............................................28

Table 8: Comparison of Miscarriage Risk Perception Before Counseling and Personal Experience with Genetic Counseling (GC) .....................................29

Table 9. Comparison of Miscarriage Risk Perception Before Counseling and

Previous Education about Amniocentesis............................................. 30

Table 10. Comparison of Miscarriage Risk Perception Before Counseling and Personal Experience with Genetic Disease and Birth Defects....................................32

Table 11. Comparison of Risk Perception Before Counseling and Personal Experience with Amniocentesis................................................................ 33

Table 12. Comparison of Miscarriage Risk Perception Before Counseling and Demographics.................................................................. 34

Table 13. Comparison of Miscarriage Risk Perception Before Counseling and Pregnancy and

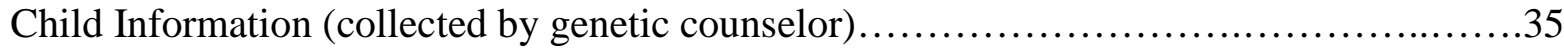

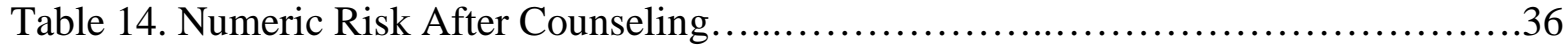

Table 15. Percentage Risk After Counseling....................................... 37

Table 16. Comparison of Risk Perception After Counseling and Demographics..............40 
Table 17. Comparison of Miscarriage Risk Perception After Counseling and Amniocentesis Plan.................................................................................41

Table 18. Comparison of Miscarriage Risk Perception After Counseling and Participants who Did Proceed with Amniocentesis.....................................................42

Table 19. Comparison of Miscarriage Risk Perception After Counseling and Participants who Did Not Proceed with Amniocentesis.....................................................43

Table 20. Comparison of Miscarriage Risk Perception After Counseling and Participants who were Unsure about proceeding with Amniocentesis.................................... 43

Table 21. Comparison of Change in Risk Perception and Demographic Factors.............47

Table 22. Comparison of Change in Risk Perception and Patient Discussions with Various Individuals.................................................................... 47

Table 23. Comparison of Change in Risk Perception and Personal Experience with Genetic Counseling.................................................................. 48

Table 24. Comparison of Change in Risk Perception and Previous Education about Amniocentesis

Table 25. Comparison of Change in Risk Perception and Personal Experience with Genetic Disease and Birth Defects.

Table 26. Comparison of Change in Risk Perception and Personal Experience with Amniocentesis......................................................................... 50

Table 27. Comparison of Change in Risk Perception and Pregnancy and Child Information.... 


\section{BACKGROUND}

Prenatal diagnostic procedures provide insight about fetal health and have become routine in obstetrical practice. These procedures provide information about the genetic, biochemical, and physiological constitution of the fetus (Eisenberg \& Wapner, 2002). Amniocentesis is the most common invasive procedure performed during pregnancy (Eddleman, et al., 2006). While amniocentesis may be routine, there are several complex aspects of the procedure that are explained to women prior to invasive testing (Hunt, de Voogd, \& Castendeda, 2005). One important factor that women consider is the risk of miscarriage associated with amniocentesis.

\section{History and Application of Amniocentesis}

In 1956, Fuchs and Riis first described the potential predictive use of the analysis of amniotic fluid. Researchers collected amniotic fluid after membrane rupture to induce labor. At this point in history, the usual indications for amniocentesis were therapeutic purposes such as reducing amniotic fluid in pregnancies affected by polyhydramnios (Woo, 2007), but not for diagnostic reasons. This fluid was analyzed to determine whether Barr bodies could be detected in amniocytes present in the amniotic fluid. The ultimate goal of the research was to propose a method for determining fetal sex before birth (Fuchs \& Riis, 1956).

Currently, amniocentesis is the most common invasive procedure used during pregnancy to detect genetic abnormalities (Eddleman, et al, 2006). Genetic amniocentesis determines fetal karyotype and the amount of amniotic fluid alpha-fetoprotein (AFP). Amniocentesis can be performed from around 15 weeks of gestation until the end of the pregnancy (Kirkham, Harris, \& Grzybowski, 2005) and is performed under direct ultrasound 
guidance using a 20- or 22-gauge spinal needle. Ultrasound is utilized to identify a pocket of fluid away from the fetus after which the spinal needle is inserted through the maternal abdomen and uterus into the amniotic fluid sac. Approximately $20 \mathrm{cc}$ of amniotic fluid is withdrawn and sent for analysis. Fetal cells floating within the amniotic fluid sample are grown in tissue culture and karyotyped to determine the presence or absence of a chromosome problem (Eisenberg \& Wapner, 2002). While the usual focus of amniocentesis is to diagnose chromosomal abnormalities, additional indications include measurement of AFP for prediction of open neural tube defects, analysis for single gene disorders, determination of the presence of infection, and determination of fetal lung maturity (Woo, 2007).

As more clinicians began performing amniocentesis, the methodology evolved. In 1985 Romero et. al. compared two different ways of performing amniocentesis procedure. One method, called the sonographically-guided technique, involved the clinician using an ultrasound transducer to locate an appropriate area of fluid to sample, removing the transducer, and inserting the needle in the selected position. A second method, called sonographically-monitored technique, consisted of continuous ultrasound visualization of the fluid pocket throughout the procedure. The study determined that when the sonographicallyguided technique was applied, 5.2\% of the procedures resulted in a bloody tap and $7.7 \%$ resulted in a dry tap. In comparison, use of the sonographically-monitored technique resulted in $1.2 \%$ of these procedures with a bloody tap and $2.0 \%$ of these procedures with a dry tap. The differences were statistically significant (Romero, et al., 1985). Following these findings, many centers began using the sonographically-monitored technique as standard practice (Woo, 2007). 
As with any invasive procedure, amniocentesis is associated with risks to the patient and fetus. Risks include complications that could potentially lead to miscarriage, such as amniotic fluid leakage, spotting, cramping, and infection (Eisenberg \& Wapner, 2002). Studies evaluating the risk of a spontaneous abortion associated with amniocentesis have had varying results.

\section{Miscarriage Risk Associated with Amniocentesis}

In the 1970s, studies began to emerge describing the risk for miscarriage with amniocentesis. Philip and Bang (1978) reported on data gathered from 1177 pregnant women who underwent amniocentesis. Of the women sampled, $28(2.4 \%)$ women experienced a spontaneous abortion. The authors reported that about $25 \%$ of the women who experienced spontaneous abortion underwent the procedure prior to 16 weeks of gestation. Investigators also noted that 11 of the 28 women "were probably already at risk of aborting" (Philip \& Bang, 1978, p. 1184) based on a variety of factors, including bleeding, cervical insufficiency, and abnormalities of the placenta. Of the remaining women who experienced a spontaneous abortion, $8(0.70 \%)$ women had their first symptom of a miscarriage within three weeks of undergoing the procedure. If three weeks following the procedure is considered to be the time for a miscarriage to occur, then the authors felt that a miscarriage risk of $0.70 \%$ should be quoted to women considering amniocentesis. Three women $(0.25 \%)$ experienced a spontaneous abortion within one week of the procedure. If one week is considered a reasonable time period for miscarriage risk, then the authors concluded that $0.25 \%$ risk should be quoted to pregnant women considering amniocentesis. Thus the authors reported 
the miscarriage rate associated with amniocentesis as $0.3-0.7 \%$. In this particular study, there was no control group (Philip \& Bang, 1978).

An investigational group in Canada also studied the pregnancy loss rate associated with amniocentesis. This study examined 1223 amniocenteses performed on 990 pregnant women with 1020 pregnancies. Thirty women had amniocenteses performed in two different pregnancies occurring during the time period of the study. The control group consisted of data gathered from vital statistics records from different national organizations in Canada on spontaneous abortions between 16 and 19 weeks gestation at several hospitals in Toronto and other Canadian cities. Demographic data was available on all pregnant women in the control group. The investigators reported that the incidence of fetal loss after amniocentesis was $4.7 \%$, which was not statistically different from the loss rate in the control group of 9164 pregnant women $(5.6 \%$ and $3.7 \%$ miscarriage rates at the two hospitals compared to the study group). The researchers concluded that the amniocentesis is a safe procedure for both the mother and the fetus (Simpson, et al., 1976).

Niermeijer et. al. performed a study that followed 350 pregnant women 38 years of age or older who underwent amniocentesis between 14 and 16 weeks of gestation (1976). Three experienced a spontaneous abortion within one month following the procedure. Of these three cases, one of the procedures was performed transvaginally due to placental location, one fetus was at risk for Pompe disease (showed deficiency of $\alpha$-1,4-glucosidase activity), and one fetus was conceived by a mother with a balanced translocation (the fetal cells failed to grow and were not available for analysis). Based on these considerations and other analyses in the study, the authors concluded that the miscarriage risk associated with 
amniocentesis was $\pm 1 \%$ (Niermeijer, Sachs, Jahodova, Tichelaar-Klepper, Kleijer, \& Galjaard, 1976).

Several other studies have indicated a variety of miscarriage rates associated with amniocentesis. In 1986, one of the few randomized trials pertaining to amniocentesis was conducted. The authors found a miscarriage rate of $1.7 \%$ among the group that underwent the amniocentesis versus a $0.7 \%$ miscarriage rate in the control group. The rate of miscarriage among the study group was significantly higher than the control group (Tabor, Madsen, Obel, Philip, Bang, \& Norgaard-Pedersen, 1986). Subsequent studies have shown risks ranging from $0.3 \%$ to $0.5 \%$, (Leschot, Verjaal, \& Treffers, 1985; Blessed, Lacoste, \& Welch, 2001).

In 1995 the Centers for Disease Control and Prevention (CDC) released a statement that reported the risk of miscarriage after amniocentesis to be between $0.25 \%$ and $0.5 \%$. This risk number was not calculated from a study or publication; rather, a committee at the CDC reviewed many different publications that described the miscarriage risk associated with amniocentesis and determined a risk number that seemed appropriate to the committee. This risk became generalized as the 1 in 200 risk routinely quoted with amniocentesis (Olney, Moore, Khoury, Erickson, Edmonds, \& Botto, 1995).

Mujezinovic and Alfirevic (2007) conducted a review of the literature on the risk of miscarriage associated with amniocentesis and analyzed various risk figures quoted by previous studies. Twenty-nine studies were found to meet criteria for analysis. After dividing the findings of these studies into larger groups for analysis, authors concluded that the risk for pregnancy loss within 14 days of the procedure was $0.6 \%$, the risk for loss of pregnancy before 24 weeks gestation was $0.9 \%$, and the total pregnancy loss after amniocentesis was $1.9 \%$. The investigators noted that only five of the studies analyzed included control groups. 
Therefore these numbers do not take into account the background risk for miscarriage (Mujezinovic \& Alefirevic, 2007).

In 2007, the American College of Obstetricians and Gynecologists (ACOG) issued a practice bulletin summarizing the miscarriage rate associated with amniocentesis after reviewing several studies on the subject (ACOG Practice Bulletin No. 88: Invasive Prenatal Testing for Aneuploidy, 2007). The committee summarized the miscarriage rate associated with amniocentesis as 1/300-1/500. This range of risk figures attempted to capture the breadth of miscarriage loss rates as quoted by various studies. This conclusion was based on "limited or inconsistent scientific evidence" (ACOG Practice Bulletin No. 88: Invasive Prenatal Testing for Aneuploidy, 2007, p. 1465), indicating that previous studies that examined the amniocentesis-associated miscarriage rate produced conflicting information regarding the exact risk figure.

Researchers stated the need to assess the miscarriage rate associated with amniocentesis using data collected in a large prospective study. The First and Second Trimester Evaluation of Risk (FASTER) trial was a large multi-center study that compared first trimester and second trimester screening techniques for the detection of Down syndrome. The trial collected data from over 35,000 pregnant women in the United States. In addition to investigating screening efficacy, data from women who chose to undergo an amniocentesis after screening were collected and compared to women in the trial who did not undergo an amniocentesis. This study found that the loss rate in the amniocentesis group was $1 / 1600$ or $0.006 \%$ higher than controls. This risk of miscarriage associated with amniocentesis was therefore concluded to be much lower than previously estimated (Eddleman, et al., 2006). 
In response to the data published from the FASTER trial, Alfirevic and Tabor published a letter to the editor voicing concerns regarding several of the procedures carried out during the study (2007). Afirevic and Tabor commented on the lack of data regarding the gauge of the needle used during the amniocentesis. Concerns were raised about the control group used in the FASTER trial: according to their reading of the study, the control group contained every case of pregnancy loss up to 24 weeks gestation and did not specify the gestational week each pregnancy loss occurred (Alfirevic \& Tabor, 2007). Alfirevic and Tabor commented that individuals in the control group could not be adequately matched to individuals who pursued the amniocentesis. The major investigators of the FASTER trial amniocentesis study replied to these concerns, stating that an informal poll of many of the investigators involved in the trial found that a majority of procedures were performed using a 22-gauge needle. In addition, the FASTER trial investigators claimed that the second statement by Alfirevic and Tabor was incorrect because each of the participants included in the analysis was required to complete the entire protocol (all women had a second trimester blood draw after 15 weeks of gestation). Therefore the patients had to be pregnant at least through 15 weeks and thus the analysis did not include first trimester losses. The trial included women who experienced pregnancy loss between gestational weeks 15 and 24, which was the time period in which the study group experienced pregnancy loss (Eddleman $\&$ Malone, 2007). 


\section{Screening for Aneuploidy}

In the United States, the main indication for discussion of amniocentesis has historically been advanced maternal age, or a woman who is age 35 years or greater at the time of delivery. The rationale for this indication stems from the increased likelihood of women with advanced age to have a child with a chromosomal abnormality, such as Down syndrome (ACOG Practice Bulletin No. 77: Screening for Fetal Chromosomal Abnormalities, 2007). More recently, ACOG recommended that amniocentesis be offered to all pregnant women, regardless of age. This change was made because women at any age can have a child with a chromosomal abnormality (ACOG Practice Bulletin No. 88: Invasive Prenatal Testing for Aneuploidy, 2007).

Modern non-invasive screening focuses on biochemical markers in maternal blood that can be used to alter the $a$ priori risk of aneuploidy. There are several screening options available during pregnancy to aid in the determination of a woman's risk for having a child with a karyotypic abnormality or structural fetal anomaly. An example of a screening technique is ultrasound, which examines the physical structures of the fetus to assess for birth defects. If a fetus has Down syndrome, soft markers or fetal abnormalities may be identified by ultrasound. However, not every pregnancy affected with Down syndrome will have soft markers or structural abnormalities. Prior studies describe that sonographic markers or abnormalities are detected in approximately $30-50 \%$ of fetuses with Down syndrome (Rotmensch, et al., 1997; Benacerraf B., 2000).

Another screening method commonly utilized is second trimester maternal serum screening, which measures the levels of various metabolites between fourteen and twentyone gestational weeks of pregnancy. Quadruple screening refers to the examination of alpha- 
fetoprotein (AFP), human chorionic gonadotropin (hCG), unconjugated estriol (uE3), and inhibin A (DIA) in the mother's blood. Second trimester maternal serum screening is the most common screening method for Down syndrome in the United States (Malone, et al, 2005). Approximately $80 \%$ of affected fetuses are detected using the quadruple screen (ACOG Practice Bulletin No. 77: Screening for Fetal Chromosomal Abnormalities, 2007).

The screening method that has been utilized in more recent years is first trimester screening, which can be performed between eleven and thirteen weeks of gestation. First trimester screening involves obtaining a nuchal translucency measurement of the fluid behind the fetal neck as well as an analysis of the analytes free or total $\beta$-hCG and pregnancyassociated plasma protein A (PAPP-A). The first trimester screen detects approximately 82$87 \%$ of all fetuses with Down syndrome, which is a higher detection rate than second trimester screening. One major advantage of the first trimester screening method is that women receive information about their risk to have an affected pregnancy at an early stage of gestation (ACOG Practice Bulletin No. 77: Screening for Fetal Chromosomal Abnormalities, 2007).

\section{Conflicting Goals of Amniocentesis}

Most practicing health care professionals who render obtetrical care view amniocentesis as a routine but invasive procedure. However, a study performed by Hunt, de Voogd, and Castendeda (2005) revealed that, while health care professionals may view prenatal screening and diagnostics as routine, pregnant women faced with the decision about whether or not to proceed with this testing do not see the procedures as routine. Hunt examined the interactions between pregnant women and their physicians discussing the 
results of their maternal serum screening test and information regarding the amniocentesis. The study found that the health care professionals and patients had drastically conflicting views of the purpose and motivations for proceeding with the amniocentesis. Clinicians viewed the decision to proceed with amniocentesis as part of an isolated medical algorithm in which very little consideration was given to the patient's personal life or experiences. In contrast, the patients viewed the amniocentesis as a way to assure themselves that everything in their pregnancy is normal (Hunt, de Voogd, \& Castendeda, 2005). The study emphasized the stark contrast between patient and clinician motivation for prenatal screening and diagnositcs; while both parties claim that these tests promote a healthy pregnancy, it became clear in the course of the study that the motivations for using these tests to achieve the goals mentioned above were very different. The authors commented that clinicians viewed prenatal screening and diagnostic testing as routine and mundane because these tests were often performed in the clinican's office. The patients who were undergoing these screening and diagnostic procedures viewed them as momentous and often frightening. These differences in viewpoint may be accounted for by considering various heurstics, or risk assessments, that are associated with decision making.

\section{Risk Perception}

When an individual evaluates risk, empirical data describing the incidence of the event being evaluated is rarely available to them; rather, individuals usually rely on other means to judge the riskiness of a situation. This risk judgment is known as a heuristic. While simplification of the understanding of risk can be useful in everyday situations, it consistently leads to misjudgments regarding the severity of risk. The way a risk is perceived can be 
altered by many factors, including the individual's personal experience with an event or how familiar an individual is with the frequency of an event occurring (Slovic, Fischhoff, \& Lichtenstein, Rating the Risk, 2000).

Risk perception has been studied in a variety of fields, including geography, anthropology, and political science. Research in the domain of psychology has evaluated how individuals utilize heuristics to evaluate risk in their life. Factors such as level of understanding of a risk and biases incorporated from outside sources affect how a person perceives risk (Slovic, The Perception of Risk, 2000).

\section{Anchoring, Representativeness, and Availability}

Amos Tversky and Daniel Kahneman introduced the concepts of anchoring, representativeness, and availability in relation to the methodology that a person uses to perceive risk (1974). These concepts are specific examples of heuristics that can be used by an individual to better understand risks that they encounter in their lives.

Representativeness describes the situation in which an outcome is assumed to result from a process and the individual making the assumption holds to a set of restrictions that the individual believes to be true. It is also described as a type of correlation-causation assumption; the more often a person experiences event $\mathrm{A}$ with event $\mathrm{B}$, the more an individual judges events A and B to be related to each other or for one to be caused by the other. Representativeness can bias an individual to perceive the riskiness of an event to be the same irrespective of the sample size being considered (Tversky \& Kahneman, 1974). For example, if a woman knows three acquaintances that have undergone amniocentesis and one 
of them miscarries, she may perceive the risk of miscarriage due to amniocentesis to be one in three when in reality the risk is much smaller.

Availability describes how perception is altered by how easily an event comes to mind. For example, if you asked a middle-aged individual the frequency of a heart attack in the population, they use examples that they can recall from their own experiences and acquaintances to report a probability. Thus, a person's perception of the risk or probability that an event will occur is influenced by their personal experiences and how easily they can recall examples in their own lives (Tversky \& Kahneman, 1974). Whenever an event is easy to imagine or recall, it creates the perception that the event occurs at a greater frequency than what empiric data support (Slovic, Fischhoff, \& Lichtenstein, Cognitive Processes and Societal Risk Taking, 2000).

Anchoring describes the situation when a person estimates a risk value by first considering an initial value (whether correct or not) and adjusting that risk using a variety of judgments to result in a final answer. In this heuristic, prior understandings of a given risk will ultimately lead to an estimate that is biased towards the initial value. Two avenues influence the final risk: the starting risk and the adjustments that are made during the evaluation process that produces the final risk calculation (Tversky \& Kahneman, 1974). Research in this area indicates that when an individual makes a judgment about a risk, the adjustments tend to be crude and haphazard. Individuals may not consider the full implications of the new information or they may over- or underestimate the importance of the new information that is being incorporated in their final risk perception (Slovic, Fischhoff, \& Lichtenstein, Cognitive Processes and Societal Risk Taking, 2000). 
Representativeness, availability, and anchoring all play a role in risk perception and probability calculation in a wide variety of contexts and applications. While these factors are predictably seen in both everyday existence and in formal research, they inevitably lead to errors that affect the ways in which a person perceives and evaluates risk. This fact is important to consider in clinical applications in which risk perception plays a role (Slovic, The Perception of Risk, 2000).

\section{Risk Perception and Genetic Counseling}

The CDC statement addressing the miscarriage rate associated with amniocentesis acknowledged the complexity of the decision to proceed with invasive prenatal diagnostic testing (Olney, Moore, Khoury, Erickson, Edmonds, \& Botto, 1995). In its statement, the committee urged health care professionals to discuss the various aspects of this decision with patients, including maternal age and family history. The statement also recommended that the benefits, risks, and limitations of amniocentesis be discussed in depth with patients so that each pregnant woman has the adequate knowledge necessary to make an informed decision regarding prenatal diagnosis (Olney, Moore, Khoury, Erickson, Edmonds, \& Botto, 1995). Although the committee's task was to empirically assess the miscarriage rate associated with prenatal diagnostic procedures, it also emphasized the importance of taking all factors into consideration before proceeding with an invasive prenatal procedure. This statement acknowledged that a decision regarding a potentially devastating outcome for a pregnant woman should be weighed against other factors besides the simple empiric risk of miscarriage associated with the procedure (Olney, Moore, Khoury, Erickson, Edmonds, \& Botto, 1995). 
A recent study by Stevens et. al. (2008) investigated whether women perceived a difference between a range of risk figures associated with amniocentesis. This study attempted to determine which factors influence risk perception the most and at what risk level women were most comfortable with proceeding with an amniocentesis. In addition, Stevens et. al. examined a variety of factors that have the potential to influence a woman's perception of miscarriage risk associated with amniocentesis including parity, utilization of maternal serum screening, and previous children born with a birth defect. Stevens found that participants did interpret the range of risk figures as different and were more likely to wish to proceed with an amniocentesis when the risk of miscarriage was quoted at a lower figure. Additionally, none of the demographic factors were significantly associated with an amniocentesis decision. This study highlighted the concept that the quoted miscarriage risk figure is an important part of the decision-making process regarding the uptake of amniocentesis. However, Stevens et. al. noted that by placing all of the risk figures together, the participants may have been anchored to the lowest risk of miscarriage quoted. The majority of participants generally understood which risk figure was lowest and thus may have been influenced to select the lowest choice because they were comparing it to higher risks. The authors suggest that further study is needed to determine how women perceive various miscarriage risks associated with amniocentesis without being influenced by a range of figures.

\section{Anchoring and Risk Perception Associated with Amniocentesis}

Although there is a quantitative risk for miscarriage with amniocentesis, this information may not be the only factor that influences a woman's perception of the 
miscarriage risk. Anchoring, or the prior perception that serves as the frame of reference for new information, may have a great impact on the perception of risk. For women who participate in a prenatal discussion regarding amniocentesis and miscarriage risk, anchoring may have a profound impact on their risk perception that is independent of the numeric risk quoted by a genetic counselor or physician. A woman's previous experience with amniocentesis or the experiences of individuals whom she knows may serve as the frame of reference for her perception of the miscarriage risk. To date, no study has specifically examined the influence that anchoring effects have on the perception of miscarriage risk associated with the amniocentesis. Therefore, this study aims to determine what factors are most likely to anchor a woman's perception of miscarriage risk associated with amniocentesis and to determine a woman's perception of miscarriage risk associated with amniocentesis before and after a genetic counseling session. This information may help both physicians and genetic counselors alike to better understand the influence that previous perceptions regarding the miscarriage risk have on the uptake of amniocentesis. 


\section{Study Recruitment}

\section{MATERIALS AND METHODS}

Surveys were offered to pregnant women who were attending prenatal appointments at a University of Texas affiliated high-risk pregnancy clinic and met eligibility requirements. In order to be eligible, the patient's indication had to involve the possibility of having an amniocentesis performed and included advanced maternal age and abnormal serum screen results. Patients were eligible to participate if they were also at least 18 years of age, spoke English, and were being seen at an IRB approved satellite clinic in the Houston, Texas area associated with the University of Texas Medical School at Houston, Department of Obstetrics, Gynecology, and Reproductive Sciences Division of Maternal Fetal Medicine: University of Texas Professional Building, Memorial Hermann Memorial City, Memorial Hermann Katy, Memorial Hermann Southeast, Memorial Hermann Southwest, and Memorial Hermann Sugar Land. A letter of invitation was given to eligible women. Those who chose to participate completed a two-part anonymous survey. Participants were recruited from September 14, 2009 to February 12, 2010.

\section{Survey Instrument}

An anonymous survey was developed to assess women's attitudes and perceptions about the miscarriage risk associated with amniocentesis. The survey was divided into three major portions. Each survey had a unique identifying number that was written onto each portion in order to match them during data analysis. The first portion was given to women while they waited for their genetic counseling appointment and provided a brief description of the amniocentesis and asked women about their perception of the miscarriage risk 
associated with amniocentesis, including questions that asked women to quantify the risk of miscarriage and rate their feelings about this risk (see Appendix A). The first portion also requested information about the participant's personal history, medical history, pregnancy history, and personal experience with various friends and family members who may have a genetic disorder. The second portion of the survey was administered after the genetic counseling session and asked participants to again quantify the risk of miscarriage associated with the amniocentesis and rate their feelings about the riskiness of the procedure (see Appendix B). This portion also asked women whether or not they were planning to undergo the amniocentesis and asked them to explain the reasons for their decision. The third portion of the survey was completed by the genetic counselor after the counseling session (see Appendix C). This portion asked the counselor to identify the various factors that they believed influenced the patient's decision whether or not to proceed with the amniocentesis. The counselor also provided pregnancy history information about the patient.

The protocol was submitted to the institutional review board of the University of Texas Health Science Center Memorial Hermann Healthcare System and approved via expedited review (UT IRB HSC-MS-09-0365).

\section{Survey Administration}

A letter of invitation was given to eligible women when they arrived at the clinic (see Appendix D). When the patient elected to participate and completed the first portion of the survey, the front desk personnel placed the letter of invitation into the patient's chart so that the genetic counselor would be aware that the patient had completed a survey. The completed survey section was placed in a separate collection box. This method ensured that the 
counselor would not be biased by the patient's responses on the first portion of the survey. The letter of invitation was given back to the participant after the completion of the genetic counseling session if requested so that the participant could have more information about the study. After the counseling session was completed, the counselor led the patient to the waiting room and gave the patient the second portion of the survey. While the patient waited for their ultrasound, they completed the second portion of the survey. The second portion was collected by the front desk personnel or ultrasonographer. The third portion of the survey was completed by the counselor after the session. Survey portions were later matched by their unique identifying number.

\section{Statistical Analysis}

The survey response fields were coded and data was entered into a Microsoft Excel spreadsheet. Statistical analysis was performed using STATA software. Information coding

for the numeric risk figure before and after counseling was converted from proportion out of 1000 to a percentage. These percentages were used in all subsequent analysis evaluating differences in risk quantification. Distribution of demographic variables (race, education, income, and religion) was described.

The perception of risk before counseling and after counseling was evaluated with respect to various factors including personal experience with amniocentesis, having a friend or relative with a genetic disease, and pregnancy information. Contingency tests were used to evaluate the differences in frequencies of each risk perception category for all the above factors. 
Changes in risk perception from before to after counseling were also calculated.

Wilcoxon signed rank test was used to compare the magnitude and direction of these changes after stratification by the factors mentioned above. 


\section{RESULTS}

Data was gathered via surveys that were administered in three main sections. The first two sections of the survey were completed by the patient and the third section was completed by the genetic counselor following the session. One hundred thirteen first sections, 104 second sections, and 110 third sections were returned. Ninety-nine surveys had all three sections completed.

It will be noted in several of the following tables and figures that not every question was completed by every participant, thereby making the sample size of certain tables smaller than the sample sizes noted above. All percentages reflect the number of participants who chose an answer out of the total for a given question. In addition, whenever comparisons were made between risk perception and a given factor, the sample size noted represents those who answered both the perception question and the question about the given factor.

\section{Demographics}

Participants were asked to indicate their race (Table 1), education level (Table 2), total household income (Table 3), and religion (Table 4a). All those who indicated their religion as "other" had the opportunity to write a description of their religion. Forty-one of 49 participants who checked "other" and wrote a description indicated items such as "Christian," "Baptist," or "Methodist," which were all grouped together under Protestantism. One participant indicated that her religion was "Catholic/Jewish." Six participants left the field blank, and 1 wrote "n/a". These 7 participants were grouped together in the category "Other" while the 41 non-Catholic Christian denominations were grouped in the category 
Protestant. Therefore the actual percentage of participants who were Protestant was 51.88\% (Table $4 \mathrm{~b}$ ). The groupings in Table $4 \mathrm{~b}$ were used in future comparisons.

Table 1. Demographics: Race

\begin{tabular}{|l|l|l|}
\hline Race & $\mathbf{n = 1 1 1}$ & Percent \\
\hline AA & 27 & $24.32 \%$ \\
\hline Hispanic & 29 & $26.13 \%$ \\
\hline Asian & 10 & $9.01 \%$ \\
\hline Caucasian & 39 & $35.14 \%$ \\
\hline Other & 6 & $5.41 \%$ \\
\hline
\end{tabular}

Table 2. Demographics: Education

\begin{tabular}{|l|l|l|}
\hline Education & $\mathbf{n = 1 1 1}$ & Percent \\
\hline Some HS & 8 & $7.21 \%$ \\
\hline HS & 25 & $22.52 \%$ \\
\hline Some College & 29 & $26.13 \%$ \\
\hline College & 34 & $30.63 \%$ \\
\hline Grad School & 15 & $13.51 \%$ \\
\hline
\end{tabular}


Table 3. Demographics: Income

\begin{tabular}{|l|l|l|}
\hline Annual Income & $\mathbf{n = 1 0 0}$ & Percent \\
\hline$<\$ 30 \mathrm{~K}$ & 34 & $34 \%$ \\
\hline$\$ 30-60 \mathrm{~K}$ & 27 & $27 \%$ \\
\hline$\$ 60-100 \mathrm{~K}$ & 16 & $16 \%$ \\
\hline$>\$ 100 \mathrm{~K}$ & 23 & $23 \%$ \\
\hline
\end{tabular}

Table 4a. Demographics: Religion

\begin{tabular}{|l|l|l|}
\hline Religion & $\mathbf{n = 1 0 6}$ & Percent \\
\hline Protestant & 14 & $13.21 \%$ \\
\hline Catholic & 27 & $25.47 \%$ \\
\hline Jewish & 1 & $0.94 \%$ \\
\hline Muslim & 4 & $3.77 \%$ \\
\hline Buddhist & 1 & $0.94 \%$ \\
\hline Hindu & 3 & $2.83 \%$ \\
\hline None & 7 & $6.6 \%$ \\
\hline Other & 49 & $46.23 \%$ \\
\hline
\end{tabular}


Table 4b: Demographics: Religion Revised

\begin{tabular}{|l|l|l|}
\hline Religion & $\mathbf{n = 1 0 6}$ & Percent \\
\hline Protestant & 55 & $51.88 \%$ \\
\hline Catholic & 27 & $25.47 \%$ \\
\hline Jewish & 1 & $0.94 \%$ \\
\hline Muslim & 4 & $3.77 \%$ \\
\hline Buddhist & 1 & $0.94 \%$ \\
\hline Hindu & 3 & $2.83 \%$ \\
\hline None & 7 & $6.60 \%$ \\
\hline Other (blank) & 7 & $6.60 \%$ \\
\hline Other (non- & 1 & $0.01 \%$ \\
\hline Protestant) & & \\
\hline
\end{tabular}

\section{Miscarriage Risk Quantification Before Counseling}

Before the genetic counseling session, patients were given the opportunity to indicate how many women out of 1000 they believed would miscarry following the amniocentesis or, if the patient preferred, to indicated the percentage of women who would miscarry following an amniocentesis. Twenty-six total responses were indicated on the first portion of the survey for the miscarriage number and 29 total responses were recorded for the percentage of women who would miscarry due to the amniocentesis. Patients provided a wide variety of responses. Lists of responses are in Tables 5 and 6. 
Table 5. Numeric Risk Before Counseling

\begin{tabular}{|l|l|}
\hline Number/1000 & $\mathbf{n = 2 6}$ \\
\hline 0 & 1 \\
\hline 1 & 7 \\
\hline 2 & 2 \\
\hline $2-3$ & 1 \\
\hline 3 & 3 \\
\hline 5 & 1 \\
\hline 10 & 1 \\
\hline 15 & 4 \\
\hline 20 & 1 \\
\hline 50 & 2 \\
\hline 100 & 1 \\
\hline 250 & \\
\hline
\end{tabular}


Table 6. Percentage Risk Before Counseling

\begin{tabular}{|c|c|}
\hline Percent & $n=29$ \\
\hline 0 & 1 \\
\hline 0.003 & 1 \\
\hline$<1 / 2$ & 1 \\
\hline 0.5 & 1 \\
\hline 1 & 5 \\
\hline $1-2$ & 2 \\
\hline 2 & 5 \\
\hline 3 & 3 \\
\hline 4 & 1 \\
\hline 5 & 4 \\
\hline 7 & 1 \\
\hline 10 & 1 \\
\hline 25 & 1 \\
\hline 40 & 1 \\
\hline 60 & 1 \\
\hline
\end{tabular}

In order to simplify the examination of the quantification of miscarriage risk perception before counseling, all of the responses given in numerical form were converted to percentages and combined with the data of participants who answered the question in percentage form. Ranges of these percentages were formed for ease of analysis. In the first portion of the survey, 8 participants answered with both a number and a percentage. Both 
number and percentage values are reflected in Tables 5 and 6 . However, only the percentage values were used in the data in Figure 1, which examines general trends of risk quantification before counseling. Figure 1 shows that most of the participants $(n=27)$ believed the risk to be between $0-1 \%$.

Figure 1. Miscarriage Risk Quantification Before Counseling (Percentage Form)

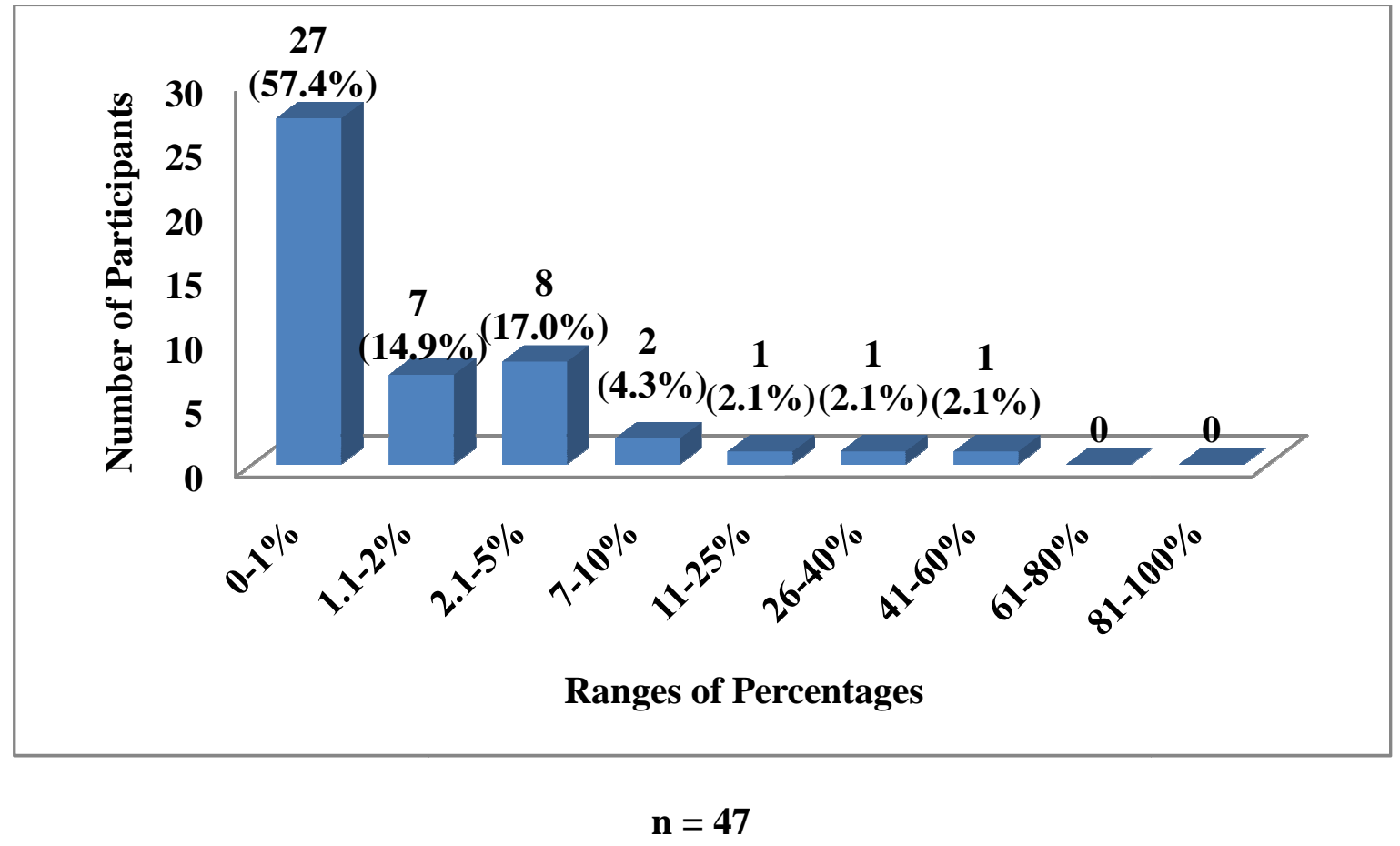

\section{Miscarriage Risk Perception Before Genetic Counseling and Various Factors}

Seventy-four participants indicated their perception of the risk of miscarriage associated with amniocentesis before counseling in Likert scale format. In general, most patients perceived the risk as low or average (Figure 2). 
Figure 2. Perception of Miscarriage Risk Before Counseling

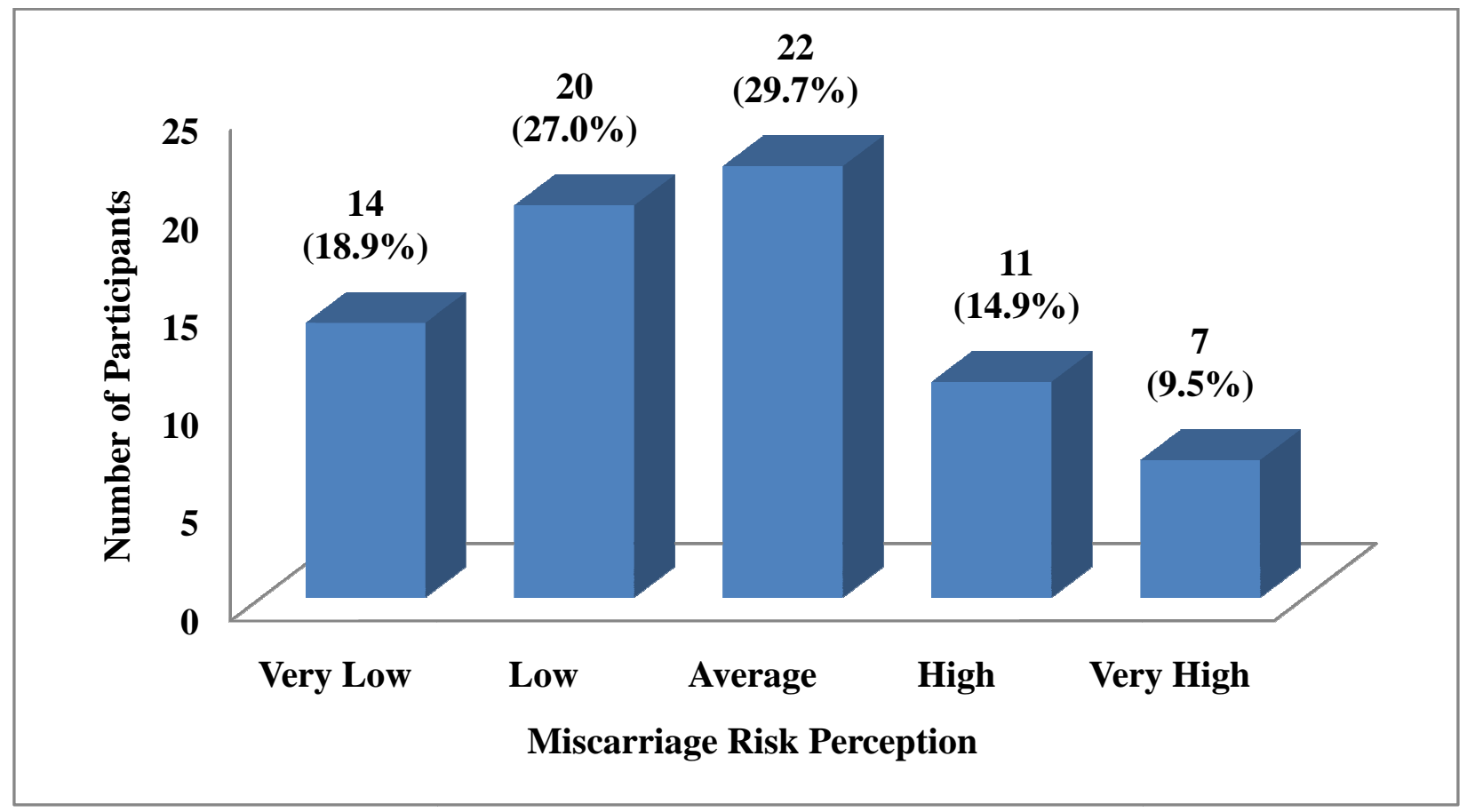

$$
\mathbf{n}=\mathbf{7 4}
$$

Responses were analyzed using Chi-square analysis to compare miscarriage risk perception and individual factors that are potentially involved in anchoring. All of the comparisons performed were between participants who indicated a given answer and those who did not indicate that answer. All of the sample sizes indicated in the tables are those who indicated the given answer. Table 7 indicates with whom the participant had discussed amniocentesis. Participants were able to indicate more than one person. Two factors approached significance: discussion of amniocentesis with a coworker $(p=0.056)$ and if a person made a suggestion about the amniocentesis to the patient $(\mathrm{p}=0.077)$. Those participants who indicated that they had spoken with a coworker $(n=13)$ tended to view the risk as average, whereas those who did not indicate they had spoken with a coworker tended 
to view the risk as low or average. A total of 60 participants completed the survey item that assessed whether or not someone offered them a suggestion about amniocentesis. Those who indicated that they were told not to pursue amniocentesis $(n=23)$ tended to view the risk as low $(n=4)$, average $(n=9)$, or high $(n=5)$ those who were told to undergo amniocentesis $(n=20)$ tended to view the risk as very low $(n=8)$ or low $(n=7)$, and those who said that the person did not give a suggestion $(n=17)$ considered the risk as almost equally low $(n=5)$, average $(n=5)$, and high $(n=4)$.

Table 7. Comparison of Miscarriage Risk Perception Before Counseling and Patient

\section{Discussions with Various Individuals}

\begin{tabular}{|l|l|l|}
\hline Comparison of Factors & $\mathbf{n}$ & p-value \\
\hline Discuss with Doctor & 51 & $\mathrm{p}=0.090$ \\
\hline Discuss with Husband & 39 & $\mathrm{p}=0.603$ \\
\hline Discuss with Mother & 20 & $\mathrm{p}=0.404$ \\
\hline Discuss with Friend & 27 & $\mathrm{p}=0.615$ \\
\hline Discuss with Coworker & 13 & $\mathrm{p}=0.056$ \\
\hline Discuss with Sister & 10 & $\mathrm{p}=0.158$ \\
\hline Discuss with Other & 7 & $\mathrm{p}=0.235$ \\
\hline Discuss with No One & 9 & $\mathrm{p}=0.175$ \\
\hline Person made an Amnio suggestion & 60 & $\mathrm{p}=0.077$ \\
\hline
\end{tabular}


Table 8 indicates that, of the people who report having genetic counseling before, most were seen for advanced maternal age. One participant indicated that they had had genetic counseling but they did not mark an indication, and one participant indicated that they had had genetic counseling in the past but indicated that they had been seen for AMA and for "other" indication. There were no significant differences seen between women with previous genetic counseling and those without genetic counseling.

Table 8: Comparison of Miscarriage Risk Perception Before Counseling and Personal Experience with Genetic Counseling (GC)

\begin{tabular}{|l|l|l|}
\hline Comparison of Factors & n & p-value \\
\hline Patients w/ previous genetic counseling & 13 & $\mathrm{p}=0.233$ \\
\hline Previous GC for AMA & 7 & $\mathrm{p}=0.341$ \\
\hline Previous GC for Pos DS & 1 & $\mathrm{p}=0.361$ \\
\hline Previous GC for Fam Hx & 1 & $\mathrm{p}=0.214$ \\
\hline Previous GC for Other Indication & 5 & $\mathrm{p}=0.548$ \\
\hline
\end{tabular}

Table 9 shows whether the way in which patients have obtained educational information about amniocentesis influences their risk perception. Participants were asked to indicate all sources they utilized. The majority of women who indicated they had obtained educational information about amniocentesis indicated doing so either via a book or the Internet. No factors were found to be statistically significant. 
Patients were asked to indicate their personal experience with a genetic disease or birth defect and could indicate more than one response. When analyzing whether having a personal experience with genetic disease and birth defects influences risk perception (Table 10), there was a statistically significant difference between miscarriage risk perception and whether or not the patient had a friend, relative, or coworker with a child or a personal history of a genetic disease $(\mathrm{p}=0.001)$. If a participant knew a friend, relative, or coworker with a personal history or a child with a genetic disease $(n=24)$, they tended to view the risk of miscarriage as lower than those who did not know a person with this history. In looking further at whether it mattered what type of friend or relative had the genetic condition, we compared specific relationships to those who did not know anyone with a genetic disease $(\mathrm{n}=47$; table 10). Two specific relationships were found to be statistically significant: knowing a friend with a genetic disease $(\mathrm{p}=0.013)$ and knowing another relative with a genetic disease $(\mathrm{p}=0.025)$. These individuals were more likely to view the risk as low.

Table 9. Comparison of Miscarriage Risk Perception Before Counseling and Previous Education about Amniocentesis

\begin{tabular}{|l|l|l|}
\hline Comparison of Factors & n & p-value \\
\hline Learned about Amnio via book & 25 & $\mathrm{p}=0.753$ \\
\hline Learned about Amnio via Pamphlet & 9 & $\mathrm{p}=0.231$ \\
\hline Learned about Amnio via Web & 33 & $\mathrm{p}=0.384$ \\
\hline Learned about Amnio via None & 23 & $\mathrm{p}=0.739$ \\
\hline Learned about Amnio via Other & 5 & $\mathrm{p}=0.132$ \\
\hline
\end{tabular}


Patients were asked to indicate their personal experience with a genetic disease or birth defect and could indicate more than one response. Analysis was conducted to compare respondents to all those who did not indicate the answer being analyzed. When analyzing whether having a personal experience with genetic disease and birth defects influences risk perception (Table 10), the only statistically significant factor was the difference between miscarriage risk perception and whether or not the patient had a friend, relative, or coworker with a child or a personal history of a genetic disease $(\mathrm{p}=0.001)$. If a participant knew a friend, relative, or coworker with a personal history or a child with a genetic disease $(n=24)$, they tended to view the risk of miscarriage as lower than those who did not know a person with this history. In looking further at whether it mattered what type of friend or relative had a genetic condition, one factor approached significance: the patient had a friend with a genetic disease $(\mathrm{p}=0.060)$. Those who have a friend with a genetic disease or a child with a genetic disease $(n=11)$ were more likely to view the risk as low $(n=6)$. 
Table 10. Comparison of Miscarriage Risk Perception Before Counseling and Personal Experience with Genetic Disease and Birth Defects

\begin{tabular}{|c|l|l|}
\hline Comparison of Factors & $\mathbf{n}$ & $\mathbf{p}$-value \\
\hline $\begin{array}{l}\text { Know a friend with child/personal hx } \\
\text { of genetic disease }\end{array}$ & $\mathbf{2 4}$ & $\mathbf{p}=\mathbf{0 . 0 0 1}$ \\
\hline Friend genetic disease hx & $\mathbf{1 1}$ & $\mathbf{p}=\mathbf{0 . 0 1 3}$ \\
\hline Mother genetic disease hx & 1 & $\mathrm{p}=0.201$ \\
\hline Sister genetic disease hx & 1 & $\mathrm{p}=0.422$ \\
\hline Sister in law genetic disease hx & 1 & $\mathrm{p}=0.422$ \\
\hline Another relative genetic disease hx & $\mathbf{7}$ & $\mathbf{p}=\mathbf{0 . 0 2 5}$ \\
\hline Coworker genetic disease hx & 2 & $\mathrm{p}=0.390$ \\
\hline Other genetic disease hx & 7 & $\mathrm{p}=0.095$ \\
\hline
\end{tabular}

Table 11 summarizes the participants' personal experience with amniocentesis. The sample sizes do not sum to the correct number because one participant marked that she had not had an amniocentesis in a previous pregnancy, yet also marked that the amniocentesis results revealed trisomy 18 . Several p-values were not calculated due to small sample sizes. No factors were found to be statistically significant. 
Table 11. Comparison of Risk Perception Before Counseling and Personal Experience with Amniocentesis

\begin{tabular}{|c|l|l|}
\hline Comparison of Factors & $\mathbf{n}$ & $\mathbf{p}$-value \\
\hline Had Amnio in Previous Pregnancy & 9 & $\mathrm{p}=0.868$ \\
\hline Previous Amnio Results were normal & 5 & Not calculated \\
\hline Previous Amnio Results were DS & 1 & Not calculated \\
\hline Previous Amnio Results were Tri 18 & 1 & Not calculated \\
\hline Previous Amnio results were other & 3 & Not calculated \\
\hline Complications after Amnio & 2 & $\mathrm{p}=0.532$ \\
\hline Bleeding following Amnio & 1 & Not calculated \\
\hline Other complication following Amnio & 1 & Not calculated \\
\hline Friend/Relative had Amnio & 25 & $\mathrm{p}=0.853$ \\
\hline Friend had Amnio & 19 & $\mathrm{p}=0.917$ \\
\hline Mother had Amnio & 2 & $\mathrm{p}=0.813$ \\
\hline Sister had Amnio & 1 & $\mathrm{p}=0.361$ \\
\hline Sister in Law had Amnio & 1 & $\mathrm{p}=0.603$ \\
\hline Another family member had Amnio & 3 & $\mathrm{p}=0.239$ \\
\hline Cowork had Amnio & 5 & $\mathrm{p}=0.177$ \\
\hline Other had Amnio & 2 & $\mathrm{p}=0.813$ \\
\hline Problem shown on friend's Amnio & 3 & $\mathrm{p}=0.138$ \\
\hline Friend had complication after Amnio & 1 & $\mathrm{p}=0.521$ \\
\hline & & \\
\hline
\end{tabular}


Demographic information is summarized in Table 12; no factors were found to be statistically significant.

Table 12. Comparison of Miscarriage Risk Perception Before Counseling and Demographics

\begin{tabular}{|l|l|l|}
\hline Comparison of Factors & n & p-value \\
\hline Race & 74 & $\mathrm{p}=0.848$ \\
\hline Education & 74 & $\mathrm{p}=0.658$ \\
\hline Income & 69 & $\mathrm{p}=0.551$ \\
\hline Religion & 72 & $\mathrm{p}=0.645$ \\
\hline
\end{tabular}

Table 13 indicates factors involving participants' pregnancy and family size information. Pregnancy information was collected from the third portion of the survey that was completed by the genetic counselor to help ensure accuracy. The sample size for each factor represents how many data points were available for analysis, not the total number of pregnancies. The only statistically significant factor was the number of total living children a participant had $(\mathrm{p}=0.038)$. Women who had one living child $(\mathrm{n}=28)$ were more likely to indicate a risk on the lower end of the range. Participants who had more than two living children were included in the analysis, but these sample sizes were much smaller and did not show an obvious trend. 
Table 13. Comparison of Miscarriage Risk Perception Before Counseling and Pregnancy and Child Information (collected by genetic counselor)

\begin{tabular}{|l|l|l|l|l|l|}
\hline Comparison of Factors & $\mathbf{n}$ & $\mathbf{n = 0}$ & $\mathbf{n = 1 - 2}$ & $\mathbf{n = 3 +}$ & $\mathbf{p}$-value \\
\hline Total pregnancies & 70 & 0 & 32 & 38 & $\mathrm{p}=0.670$ \\
\hline Total living children & 70 & 15 & 45 & 10 & $\mathbf{p}=\mathbf{0 . 0 3 8}$ \\
\hline Total miscarriages & 69 & 47 & 18 & 4 & $\mathrm{p}=0.759$ \\
\hline Total abortions/terminations & 70 & 54 & 15 & 3 & $\mathrm{p}=0.104$ \\
\hline Total stillbirths & 70 & 68 & 2 & 0 & $\mathrm{p}=0.317$ \\
\hline Previous child with a birth defect & 10 & $\mathrm{n} / \mathrm{a}$ & $\mathrm{n} / \mathrm{a}$ & $\mathrm{n} / \mathrm{a}$ & $\mathrm{p}=0.115$ \\
\hline
\end{tabular}

\section{Miscarriage Risk Quantification After Counseling}

Participants were asked to quantify the miscarriage risk associated with amniocentesis after they had received genetic counseling. Sixty-five total responses were recorded in the format where the participant indicated the number of women out of 1000 and 43 total responses were completed for the percentage of women that would miscarry because of the amniocentesis. A list of the responses is compiled in Tables 14 and 15. 
Table 14. Numeric Risk After Counseling

\begin{tabular}{|c|c|}
\hline Number/1000 & $n=65$ \\
\hline 0 & 1 \\
\hline 0.0005 & 1 \\
\hline 1 & 11 \\
\hline $1 / 3$ & 1 \\
\hline $1 / 300$ & 4 \\
\hline $1 / 500$ & 1 \\
\hline 10 & 1 \\
\hline 100 & 1 \\
\hline 2 & 4 \\
\hline 20 & 2 \\
\hline 3 & 20 \\
\hline 3.25 & 1 \\
\hline 3.3 & 2 \\
\hline 3.5 & 3 \\
\hline $3 / 100$ & 1 \\
\hline 30 & 1 \\
\hline 300 & 2 \\
\hline 4 & 1 \\
\hline 5 & 2 \\
\hline 50 & 4 \\
\hline 6 & 1 \\
\hline
\end{tabular}


Table 15. Percentage Risk After Counseling

\begin{tabular}{|c|c|}
\hline Percentage & $n=43$ \\
\hline $1 / 300$ & 1 \\
\hline 0.05 & 1 \\
\hline 0.3 & 1 \\
\hline 0.5 & 3 \\
\hline$<1 \%$ & 2 \\
\hline 1 & 12 \\
\hline 1.5 & 1 \\
\hline 1.99 & 1 \\
\hline 2 & 6 \\
\hline 2.5 & 2 \\
\hline 3 & 2 \\
\hline 5 & 1 \\
\hline 10 & 3 \\
\hline 30 & 2 \\
\hline 60 & 1 \\
\hline 90 & 1 \\
\hline 95.2 & 1 \\
\hline 98 & 1 \\
\hline 99 & 1 \\
\hline
\end{tabular}


As with the first portion of the survey, all of the responses were converted to percentages and put into ranges for ease of comparison. For this question, 18 participants answered both with a numeral and a percentage. In these cases, the percentage that was indicated by the participant was used in the comparison. Figure 3 indicates that the vast majority of patients believed that the risk was between $0-1 \%$ after counseling.

\section{Figure 3. Miscarriage Risk Quantification After Counseling (Percentage Form)}

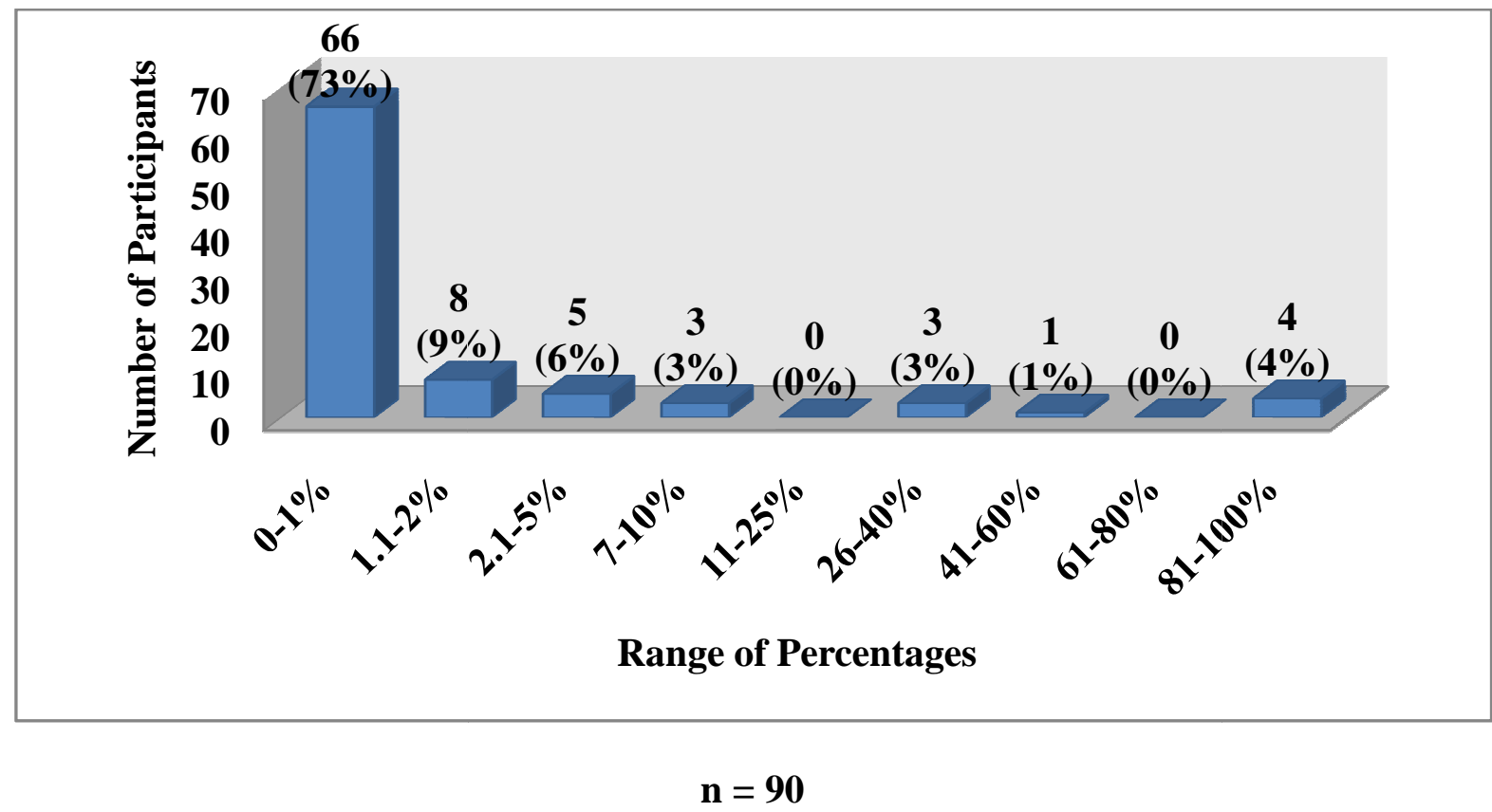

Figure 4 illustrates the comparison of miscarriage risk quantification before and after the counseling session. The percentage of each set of responses (before counseling and after counseling) are indicated on the graph. Most patients, both before and after counseling, indicated that the risk of miscarriage associated with amniocentesis was $1 \%$ or less. There is 
a statistically significant difference between risk quantification before and after counseling $(\mathrm{p}<0.0001)$ such that more participants indicated the correct numeric range post-counseling.

Figure 4. Comparison of Miscarriage Risk Quantification Before and After Counseling (Percentages)

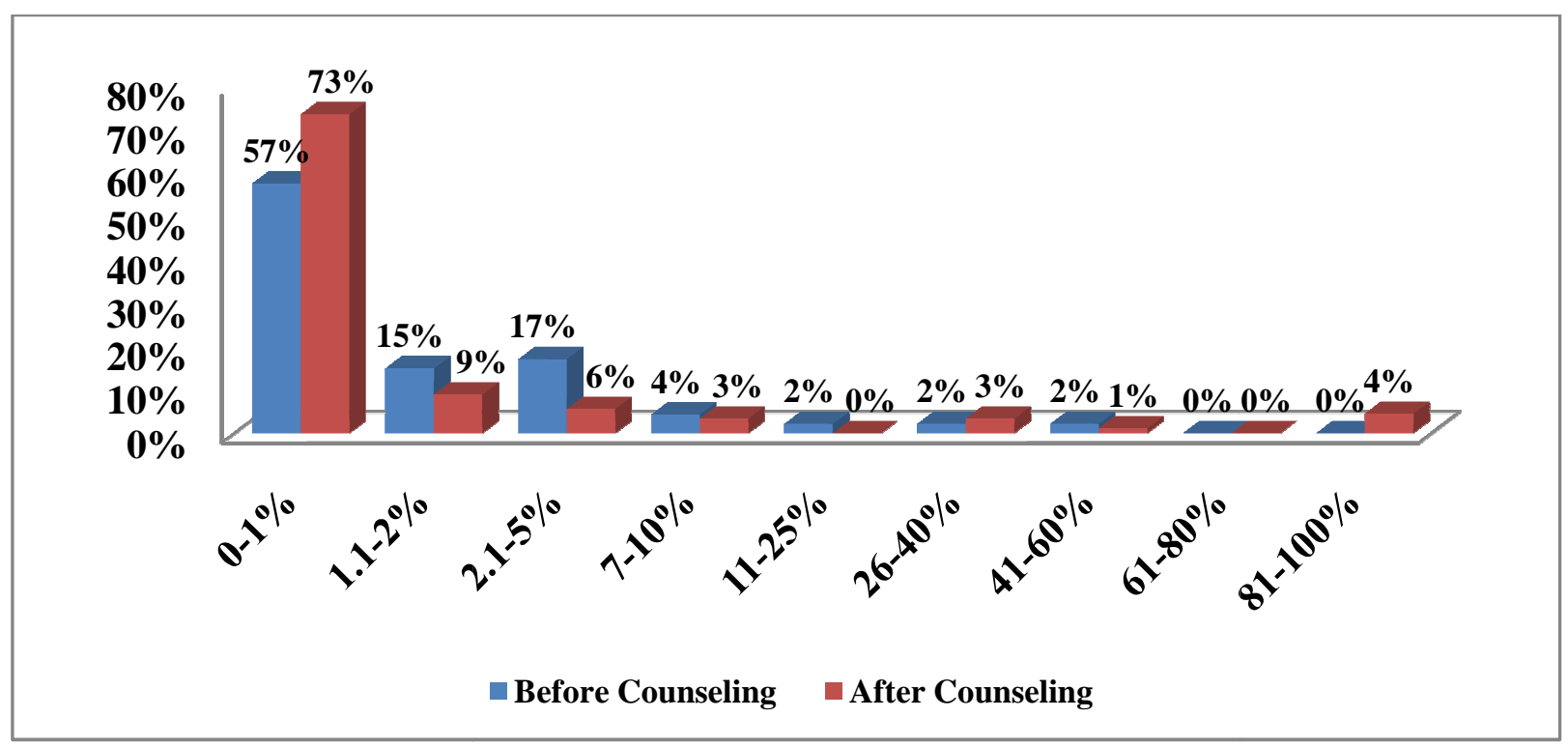

\section{Miscarriage Risk Perception After Genetic Counseling and Various Factors}

A total of 100 participants indicated their perception of the amniocentesis miscarriage risk after genetic counseling in Likert scale format. Most respondents perceived the risk as either very low $(n=25)$ or low $(n=31)$ after counseling (Figure 5). 
Figure 5. Perception of Miscarriage Risk After Counseling

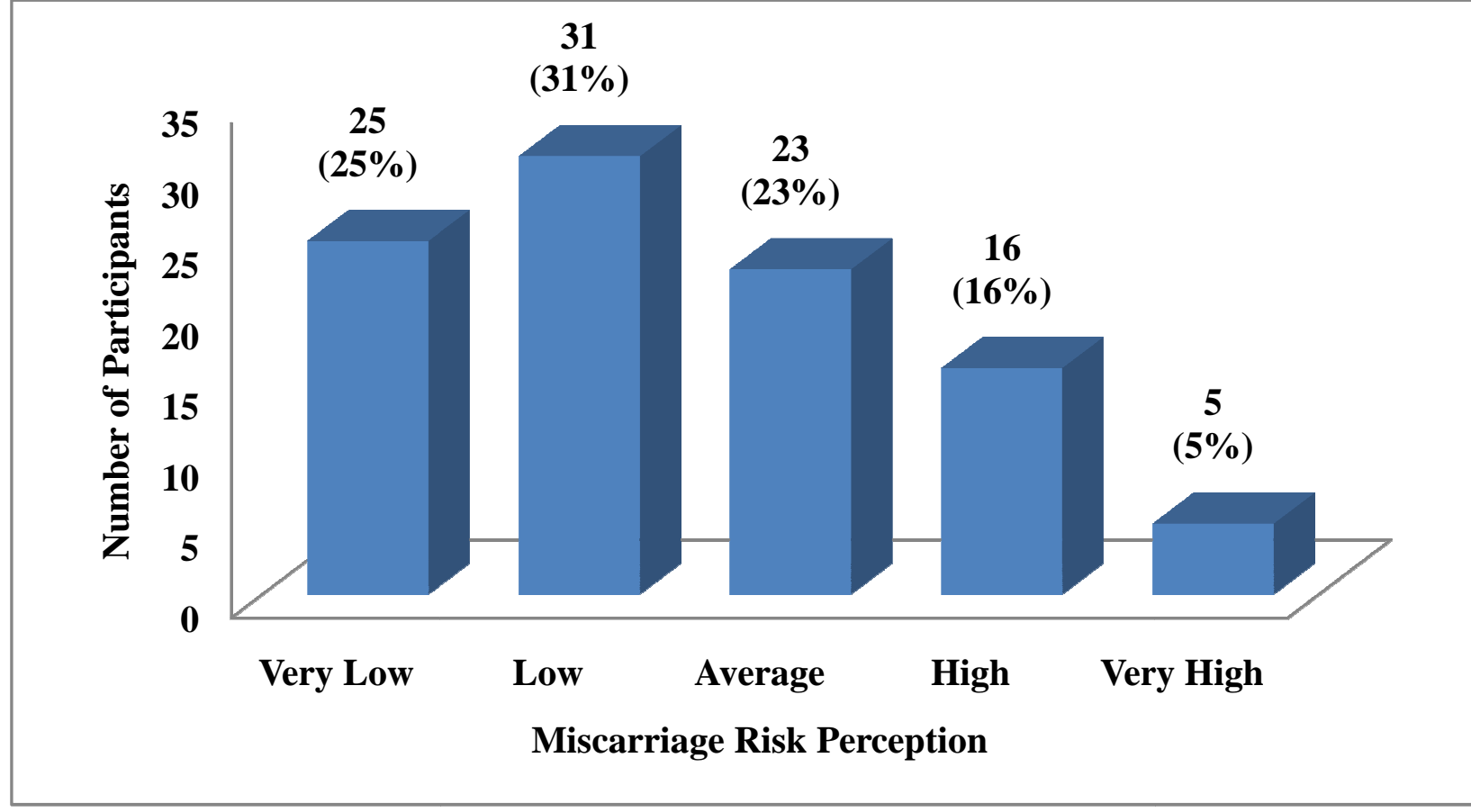

$$
\mathrm{n}=\mathbf{1 0 0}
$$

Miscarriage risk perception after counseling was compared to demographic factors. None of the factors were found to be statistically significant (Table 16).

Table 16. Comparison of Risk Perception After Counseling and Demographics

\begin{tabular}{|l|l|l|}
\hline Comparison of Factors & $\mathbf{n}$ & p-value \\
\hline Race & 93 & $\mathrm{p}=0.408$ \\
\hline Education & 93 & $\mathrm{p}=0.478$ \\
\hline Income & 84 & $\mathrm{p}=0.805$ \\
\hline Religion & 90 & $\mathrm{p}=0.513$ \\
\hline
\end{tabular}


The second portion of the survey was analyzed to examine factors potentially influencing risk perception. Analysis revealed that there was a statistically significant difference between miscarriage risk perception after genetic counseling and the patient's plan about whether or not to proceed with amniocentesis $(\mathrm{p}=0.017)$. In general, those who desired to proceed with amniocentesis usually viewed miscarriage risk as lower than those who did not elect amniocentesis (Table 17).

Table 17. Comparison of Miscarriage Risk Perception After Counseling and Amniocentesis Plan

\begin{tabular}{|l|l|l|l|l|}
\cline { 2 - 5 } \multicolumn{1}{c|}{} & \multicolumn{3}{l}{ Amniocentesis Decision } & \multicolumn{1}{l}{} \\
\hline Perception & No & Yes & Unsure & Totals \\
\hline Very Low & 5 & 17 & 3 & 25 \\
\hline Low & 10 & 10 & 8 & 28 \\
\hline Average & 10 & 7 & 3 & 20 \\
\hline High & 8 & 2 & 3 & 13 \\
\hline Very High & 5 & 1 & 0 & 6 \\
\hline Totals & $\mathbf{3 8}$ & $\mathbf{3 7}$ & $\mathbf{1 7}$ & $\mathbf{9 2}$ \\
\hline
\end{tabular}

Table 18 presents information about those who chose to proceed with amniocentesis and their reasons for desiring amniocentesis. Participants could select as many survey items as they desired. There was a statistically significant association between reduced miscarriage 
risk perception and patients who chose to proceed with the amniocentesis because they needed to know whether or not the pregnancy had a chromosomal condition $(p=0.015)$.

Table 18. Comparison of Miscarriage Risk Perception After Counseling and Participants who Did Proceed with Amniocentesis

\begin{tabular}{|l|l|l|}
\hline Comparison of Factors & $\mathbf{n}$ & $\mathbf{p}$-value \\
\hline Patient needed to know whether pregnancy had a & 34 & $\mathbf{p}=\mathbf{0 . 0 1 5}$ \\
\hline chromosomal condition & 11 & $\mathrm{p}=0.296$ \\
\hline Patient had Amnio in previous pregnancy & 4 & $\mathrm{p}=0.429$ \\
\hline Other reason for proceeding with Amnio & 1 & $\mathrm{p}=0.553$ \\
\hline
\end{tabular}

Of those participants who decided not to proceed with amniocentesis, one item was statistically significant: those who chose not to proceed with the amniocentesis because the patient felt the risk of miscarriage associated with amniocentesis was too high $(\mathrm{p}=0.004)$ (Table 19). Most people who indicated they did not want to proceed with amniocentesis $(n=18)$ for this reason perceived the risk as average $(n=7)$ or high $(n=5)$. 
Table 19. Comparison of Miscarriage Risk Perception After Counseling and Participants who Did Not Proceed with Amniocentesis

\begin{tabular}{|l|l|l|}
\hline Comparison of Factors & $\mathbf{n}$ & p-value \\
\hline The risk assoc. with Amnio is too high & 18 & $\mathbf{p}=\mathbf{0 . 0 0 4}$ \\
\hline Patient does not like needles & 9 & $\mathrm{p}=0.131$ \\
\hline $\begin{array}{l}\text { Does not matter to patient if pregnancy has } \\
\text { chromosomal condition }\end{array}$ & 12 & $\mathrm{p}=0.965$ \\
\hline Patient's friend had problem w/ Amnio & 1 & $\mathrm{p}=0.670$ \\
\hline $\begin{array}{l}\text { Patient does not know what Amnio can tell } \\
\text { her }\end{array}$ & 1 & $\mathrm{p}=0.670$ \\
\hline Patient does not believe pregnancy has a & 12 & \\
problem & & $\mathrm{p}=0.683$ \\
\hline
\end{tabular}

Finally, we examined data from those who indicated they were unsure about amniocentesis (Table 20). None of the factors examined were found to be significant.

Table 20. Comparison of Miscarriage Risk Perception After Counseling and Participants who were Unsure about proceeding with Amniocentesis

\begin{tabular}{|l|l|l|}
\hline Comparison of Factors & n & p-value \\
\hline $\begin{array}{l}\text { The patient wanted to discuss } \\
\text { Amniocentesis with Husband/Partner }\end{array}$ & 4 & $\mathrm{p}=0.813$ \\
\hline $\begin{array}{l}\text { The patient wanted to wait for the results of } \\
\text { the ultrasound }\end{array}$ & 21 & $\mathrm{p}=0.098$ \\
\hline
\end{tabular}


There were a total of six prenatal counselors involved in counseling the study participants. Risk perception after counseling was compared to the counselor who facilitated the session. There was no difference found between counselors ( $\mathrm{p}=0.723)$. In 13 cases, the majority of the genetic counseling session was performed by a second year genetic counseling student. There was no significant difference between the risk perceptions of patients who were counseled by students instead of counselors $(\mathrm{p}=0.906)$.

\section{Change in Miscarriage Risk Perception Before and After Genetic Counseling}

A comparison was made between the responses of all 65 participants who indicated a risk perception before counseling and any participant who indicated their perception after the genetic counseling session. There was a statistically significant difference between the risk perception before and after the genetic counseling session $(\mathrm{p}<0.0001)$. Additionally, analysis using Wilcoxon signed rank test was obtained to determine the differences between the risk perception before and after the genetic counseling session. This analysis also yielded a statistically significant result $(\mathrm{p}=0.022)$. Therefore, participants perceived the miscarriage risk associated with amniocentesis as lower after genetic counseling.

We compared the degree to which the genetic counseling session changed the way participants perceived the miscarriage risk of amniocentesis. Figure 6 illustrates the total change indicated by participants. A negative change indicates that the patient perceived the risk as lower on the Likert scale after the counseling session compared to their perception before counseling, whereas a positive change denotes that a participant felt the risk was higher after the session. A majority of patients did not change their perception after the counseling session (60\%) or changed their perception to a slightly lower risk (26.2\%). 
Figure 6. Change in Risk Perception

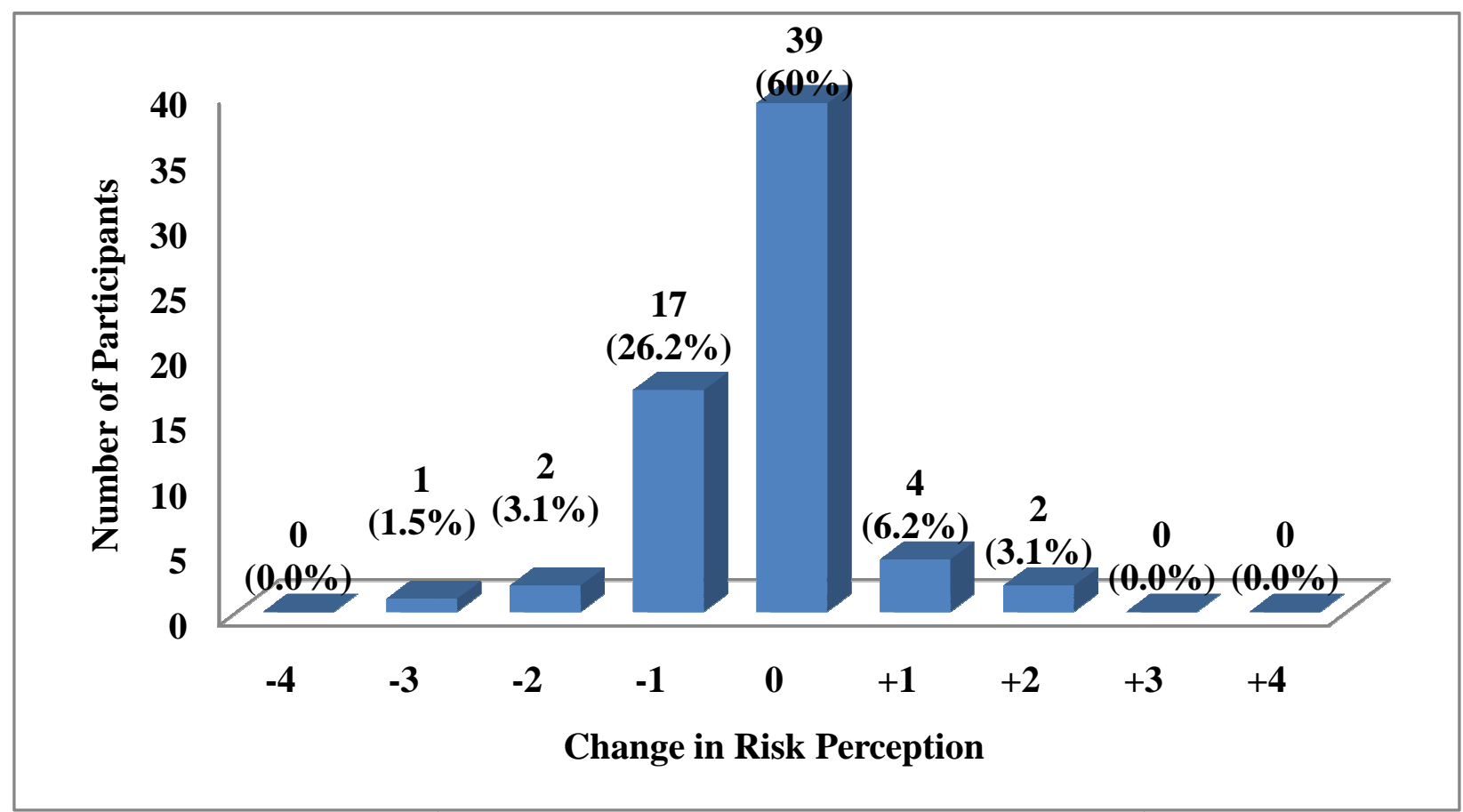

We examined whether the initial risk category influenced how much the patient's risk perception changed. Figure 7 illustrates that, in general, women did not change their perception regardless of category. However, of those who did change their risk perception after counseling, most generally moved to a lower level of risk perception about amniocentesis. 
Figure 7. Degree of Change in Risk Perception Before and After Counseling

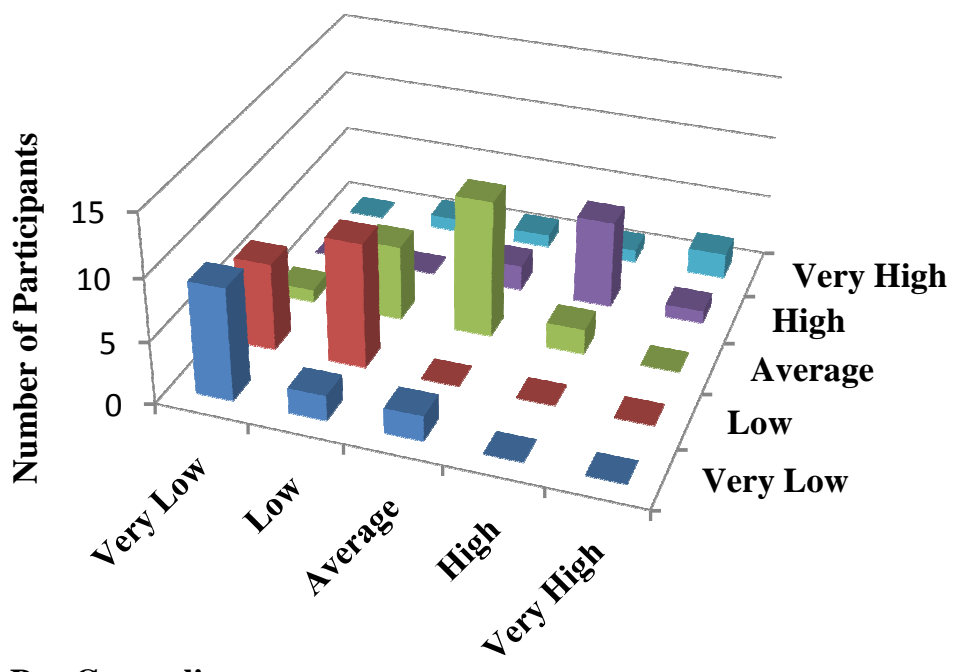

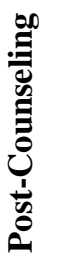

Pre-Counseling

We then compared whether women who changed their risk perception were any more or less likely to be influenced by a particular factor. There were no significant findings for demographic factors (Table 21), with whom the participant discussed amniocentesis (Table 22), or individual experience with previous genetic counseling (Table 23). There were also no significant factors when examining education about amniocentesis (Table 24). 
Table 21. Comparison of Change in Risk Perception and Demographic Factors

\begin{tabular}{|l|l|l|}
\hline Comparison of Factors & n & p-value \\
\hline Race & 65 & $\mathrm{p}=0.706$ \\
\hline Education & 65 & $\mathrm{p}=0.798$ \\
\hline Income & 60 & $\mathrm{p}=0.850$ \\
\hline Religion & 63 & $\mathrm{p}=0.999$ \\
\hline
\end{tabular}

Table 22. Comparison of Change in Risk Perception and Patient Discussions with Various Individuals

\begin{tabular}{|l|l|l|}
\hline Comparison of Factors & $\mathbf{n}$ & p-value \\
\hline Discuss with Dr. & 45 & $\mathrm{p}=0.678$ \\
\hline Discuss with Husband & 35 & $\mathrm{p}=0.530$ \\
\hline Discuss with Mother & 20 & $\mathrm{p}=0.517$ \\
\hline Discuss with Friend & 23 & $\mathrm{p}=0.381$ \\
\hline Discuss with Coworker & 11 & $\mathrm{p}=0.941$ \\
\hline Discuss with Sister & 9 & $\mathrm{p}=0.703$ \\
\hline Discuss with Other & 7 & $\mathrm{p}=0.461$ \\
\hline Discuss with No One & 7 & $\mathrm{p}=0.538$ \\
\hline Person made an Amnio suggestion & 22 & $\mathrm{p}=0.824$ \\
\hline
\end{tabular}


Table 23. Comparison of Change in Risk Perception and Personal Experience with Genetic Counseling

\begin{tabular}{|l|l|l|}
\hline Comparison of Factors & $\mathbf{n}$ & p-value \\
\hline Patients w/ previous genetic counseling & 11 & $\mathrm{p}=0.854$ \\
\hline Previous GC for AMA & 5 & $\mathrm{p}=0.950$ \\
\hline Previous GC for Pos DS & 1 & $\mathrm{p}=0.984$ \\
\hline Previous GC for Fam Hx & 1 & $\mathrm{p}=0.984$ \\
\hline Previous GC for Other Indication & 5 & $\mathrm{p}=0.946$ \\
\hline
\end{tabular}

Table 24. Comparison of Change in Risk Perception and Previous Education about Amniocentesis

\begin{tabular}{|l|l|l|}
\hline Comparison of Factors & $\mathbf{n}$ & p-value \\
\hline Learned about Amnio via book & 21 & $\mathrm{p}=0.335$ \\
\hline Learned about Amnio via Pamphlet & 7 & $\mathrm{p}=0.795$ \\
\hline Learned about Amnio via Web & 30 & $\mathrm{p}=0.273$ \\
\hline Did not learn about Amnio & 21 & $\mathrm{p}=0.084$ \\
\hline Learned about Amnio via Other & 3 & $\mathrm{p}=0.836$ \\
\hline
\end{tabular}


When change in risk perception was compared to personal experience with genetic disease, the only factor found to be significant was if the participant knew another person not specified in the choices listed who had some sort of personal history with genetic disease $(\mathrm{p}=0.036) ;($ Table 25). Of the 5 who responded, three did not change their risk perception and two increased their risk perception by one unit. Respondents tended to think that the risk associated with amniocentesis before counseling was very low $(n=2)$ or low $(n=2)$. No significance was seen between change in risk perception and personal experience with amniocentesis (Table 26). Some p-values were not calculated due to the small sample sizes in the groups indicated.

Table 25. Comparison of Change in Risk Perception and Personal Experience with Genetic Disease and Birth Defects

\begin{tabular}{|c|l|l|}
\hline Comparison of Factors & $\mathbf{n}$ & p-value \\
\hline $\begin{array}{l}\text { Know a friend with child/personal hx of } \\
\text { genetic disease }\end{array}$ & 21 & $\mathrm{p}=0.214$ \\
\hline Friend genetic disease hx & 11 & $\mathrm{p}=0.254$ \\
\hline Mother genetic disease hx & 1 & $\mathrm{p}=0.984$ \\
\hline Sister genetic disease hx & 1 & $\mathrm{p}=0.984$ \\
\hline Sister in Law genetic disease hx & 1 & $\mathrm{p}=0.984$ \\
\hline Another fam mem genetic disease hx & 6 & $\mathrm{p}=0.883$ \\
\hline Coworker genetic disease hx & 2 & $\mathrm{p}=0.979$ \\
\hline Other genetic disease hx & 5 & $\mathbf{p}=\mathbf{0 . 0 3 6}$ \\
\hline Child with birth defect & 7 & $\mathrm{p}=0.843$ \\
\hline
\end{tabular}


Table 26. Comparison of Change in Risk Perception and Personal Experience with Amniocentesis

\begin{tabular}{|c|l|l|}
\hline Comparison of Factors & $\mathbf{n}$ & p-value \\
\hline Had Amnio in Previous Pregnancy & 6 & $\mathrm{p}=0.901$ \\
\hline Previous Amnio Results were normal & 5 & Not calculated \\
\hline Previous Amnio Results were DS & 0 & Not calculated \\
\hline Previous Amnio Results were Tri 18 & 1 & Not calculated \\
\hline Previous Amnio results were other & 2 & Not calculated \\
\hline Complications after Amnio & 1 & $\mathrm{p}=0.905$ \\
\hline Bleeding following Amnio & 1 & Not calculated \\
\hline Other complication following Amnio & 0 & Not calculated \\
\hline Friend/Relative had Amnio & 21 & $\mathrm{p}=0.664$ \\
\hline Friend had Amnio & 16 & $\mathrm{p}=0.865$ \\
\hline Mother had Amnio & 1 & $\mathrm{p}=0.984$ \\
\hline Sister had Amnio & 1 & $\mathrm{p}=0.984$ \\
\hline Sister in Law had Amnio & 1 & $\mathrm{p}=0.702$ \\
\hline Another Family member had Amnio & 3 & $\mathrm{p}=0.991$ \\
\hline Cowork had Amnio & 5 & $\mathrm{p}=0.946$ \\
\hline Other had Amnio & 1 & $\mathrm{p}=0.720$ \\
\hline Problem shown on friend's Amnio & 3 & $\mathrm{p}=0.416$ \\
\hline Friend had complication after Amnio & 1 & $\mathrm{p}=0.458$ \\
\hline
\end{tabular}


When comparing risk perception change and pregnancy history (Table 27), two factors were found to be significant: total number of living children $(n=64 ; p=0.002)$ and total number of still births $(n=64 ; p=<0.001)$. Parity was distributed among a large number of responses (from 0 to 5 living children), making it difficult to determine an obvious trend. Only 2 women had a history of stillbirth.

Table 27. Comparison of Change in Risk Perception and Pregnancy and Child Information

\begin{tabular}{|l|l|l|l|l|l|}
\hline Comparison of Factors & $\mathbf{n}$ & $\mathbf{n}=\mathbf{0}$ & $\mathbf{n = 1 - 2}$ & $\mathbf{n = 3 +}$ & $\mathbf{p}$-value \\
\hline Total pregnancies & 64 & 0 & 30 & 34 & $\mathrm{p}=0.167$ \\
\hline Total living children & 64 & 13 & 43 & 8 & $\mathbf{p}=\mathbf{0 . 0 0 2}$ \\
\hline Total miscarriages & 64 & 42 & 18 & 4 & $\mathrm{p}=0.306$ \\
\hline Total abortions/terminations & 64 & 49 & 14 & 1 & $\mathrm{p}=0.203$ \\
\hline Total stillbirths & 64 & 62 & 2 & 0 & $\mathbf{p}=<\mathbf{0 . 0 0 0 1}$ \\
\hline Previous child with a birth & 8 & $\mathrm{n} / \mathrm{a}$ & $\mathrm{n} / \mathrm{a}$ & $\mathrm{n} / \mathrm{a}$ & $\mathrm{p}=0.652$ \\
defect & & & & & \\
\hline
\end{tabular}




\section{DISCUSSION}

Amniocentesis is the most common invasive procedure performed during pregnancy (Eddleman et. al. 2006). There is a risk of miscarriage associated with amniocentesis. This risk has been quoted as high as 1/200 (Olney, Moore, Khoury, Erickson, Edmonds, \& Botto, 1995) to as low as 1/1600 (Eddleman et. al. 2006). Typically, a woman who is considering undergoing amniocentesis will discuss the risks, benefits, and limitations with a knowledgeable health care professional. Regardless of the specific risk of miscarriage quoted, patients bring their own perception of the risk to the discussion. The purpose of the current study was to determine what factors potentially anchor a woman's perception of the miscarriage risk.

\section{Miscarriage Quantification and Risk Perception Before Counseling}

Participants were asked to quantify the risk of miscarriage associated with amniocentesis before they spoke with a genetic counselor. Over half of the women (57\%; $\mathrm{n}=27)$ responded that they believed the risk to be $1 \%$ or less while $14.8 \%(n=7)$ thought the risk was $1.1-2 \%$ and $17 \%(\mathrm{n}=8)$ thought the risk was $2.1-5 \%$. The remaining 5 participants indicated the risk as larger than these ranges. These results indicate that, while many women may not know the exact risk of miscarriage, approximately half estimate the risk similar to the risks quoted in the literature (ACOG Practice Bulletin No. 88: Invasive Prenatal Testing for Aneuploidy, 2007; Eddleman et. al., 2006). However, a significant portion of women overestimate the numeric risk associated with amniocentesis. Thus genetic counselors and maternal fetal specialists have a role in rectifying the understanding of a substantial number of patients. 
When asked to rate how they perceive the risk on a Likert scale of very low to very high, most women indicated that they perceived the risk of miscarriage as average (29.7\%; $\mathrm{n}=22)$ to low $(27 \% ; \mathrm{n}=20)$ before counseling. There was a generally normal distribution across the risk perception scale. These results indicate that most women view amniocentesis as a procedure with moderate to limited risk involved. Given that individuals may over- or underestimate the importation of new information when altering their original risk perception, understanding the risk perception brought to the genetic counseling session is essential (Slovic, Fischhoff, \& Lichtenstein, Cognitive Processes and Societal Risk Taking, 2000).

\section{Factors that Potentially Anchor Miscarriage Risk Perception Before Counseling}

When multiple comparisons were made between risk perception and various factors postulated to cause anchoring, only two variables were statistically significant: connection to a genetic condition and parity. Of those who indicated that they knew a person with a personal history of a genetic disease or a child with a genetic disease $(n=24)$, most tended to perceive the risk of miscarriage as low $(58.3 \%$; $n=14)$ whereas those who did not know a friend or relative with this history were more likely to perceive the risk as average (40.4\%; $\mathrm{n}=19),(\mathrm{p}=0.001)$. When compared to women who knew no one with a genetic disease, additional analysis revealed a statistically significant difference in risk perception before counseling and those who knew a friend $(\mathrm{p}=0.013)$ or another family member not specified in previous choices $(\mathrm{p}=0.025)$. Women who indicated that they had this personal experience with genetic disease had lower risk perception before counseling than those who said that they did not know anyone with this history. Based on these results, it appears that those 
participants who had some experience with a genetic disease felt that the risk of miscarriage associated with amniocentesis was lower than those who did not have connections to a genetic disease. If a person has experience with a genetic disease, they are more likely to be concerned that their own pregnancy may be affected with a genetic disease since they are able to call specific examples of the risk to mind (Weil, 2000). Research suggests that feelings towards the health of the pregnancy influence the decisions that women make regarding prenatal procedures: if women feel like the pregnancy is healthy, then amniocentesis is considered unnecessary in their minds (Markens et. al., 2010). Perhaps having a personal representation of genetic disease anchors women to a higher perception of the risk of genetic disease in their pregnancy, therefore causing the amniocentesis risk to seem smaller in comparison. In turn, they may have a stronger desire to undergo prenatal testing so that they are prepared for the potential diagnosis of a genetic condition.

There was also a statistically significant association between risk perception and the number of living children a participant had $(\mathrm{p}=0.038)$. As indicated in Table 13, 45 women had 1 or 2 living children. Women who had one living child $(\mathrm{n}=28)$ were more likely to view the risk as lower than nulliparous women. Research suggests that nulliparous women are more likely to be undecided about whether or not to proceed with amniocentesis than those who have children (Vergani et. al., 2002). Perhaps individuals who already have a child are less scared about losing a pregnancy as a result of an invasive diagnostic procedure.

Risk perception was stratified by a number of factors including demographics, discussions with various individuals about amniocentesis, personal experience with genetic counseling, previous education about amniocentesis, and personal experience with amniocentesis, and no other factors were found to be statistically significant. Therefore, what 
anchors each person to a certain risk perception appears to be multifaceted and individual. A person's individual life experiences and internal assessments influence their ultimate risk perception and these experiences are diverse (Weil, 2000). Research suggests that women making decisions regarding prenatal testing tend to rely on highly personal opinions, such as ethical convictions and emotional responses to invasive testing (Garcia et. al., 2007). Because risk perception is apparently such a personalized phenomenon, it highlights the need for highly trained health professionals such as genetic counselors to elucidate the factors for each patient and tailor the details of the session for the patient's individual needs.

\section{Miscarriage Quantification and Risk Perception After Counseling}

We also aimed to determine the participants' perception of miscarriage risk after counseling. The majority of patients perceived the risk in the correct numeric range of between $0 \%$ and $1 \%$ after counseling $(73.3 \% ; n=66)$. This figure is significantly increased from the $58.3 \%$ that indicated $<1 \%$ before the genetic counseling session $(\mathrm{p}<0.0001)$. Therefore, patients' perception of the numerical risk associated with amniocentesis is more likely to be in the correct range after counseling. While many patients had difficulty describing the numeric risk of amniocentsis, they appeared to have a general understanding that the risk is relatively low ( $1 \%$ or less). Genetic counselors use their specialized training to ascertain the patient's understanding of the topics discussed during the session, including the risk associated with invasive procedures. This training and preparation allows the counselor to provide the information in the most effective way for each patient (Weil, 2000). Because a higher percentage of patients are correct in their risk quantification post-counseling, this may 
indicate that the counseling session is a good source of education for patients seeking information about prenatal diagnostic procedures.

Four participants (4.4\%) indicated that the risk of miscarriage associated with amniocentesis was between 81 and $100 \%$ after counseling. One of these participants indicated that she thought 1 out of 1000 procedures would result in a miscarriage, but also wrote that the risk of miscarriage was $99 \%$. Another participant indicated that she believed 50 out of 1000 procedures would end in miscarriage (5\%), but converted this number to $95.2 \%$ on the survey. These cases are clear examples of non-comprehension of the mathematical concepts needed to covert a ratio to a percentage. This finding is not unexpected because previous studies have shown that people have difficulty with fractions (Gates, 2004; Stevens et. al., 2008). Two other participants indicated that the risks were 90\% and $98 \%$, with no numeric quantification for comparison. None of these participants completed the miscarriage risk quantification question in the first portion of the survey. Therefore, we cannot determine if the post-counseling risk quantification responses are different than the patient's initial belief regarding miscarriage risk before counseling.

\section{Factors that Potentially Anchor Miscarriage Risk Perception After Counseling}

There was a statistically significant association between participants' perception of the risk after the genetic counseling session and their plan about whether or not to proceed with amniocentesis $(\mathrm{p}=0.017)$. Approximately equal numbers of participants indicated that they would proceed with amniocentesis $(n=37)$ and would not proceed with amniocentesis $(n=38)$. Participants who indicated that they would proceed with amniocentesis were more likely to view the risk as very low $(45.9 \% ; n=17)$ or low $(27 \% ; n=10)$ whereas those 
participants who did not wish to proceed with amniocentesis were more likely to indicate values on the higher side of the scale $(\mathrm{p}=0.004)$. These results indicate that women who desire amniocentesis perceive the risk as lower than those who do not want to undergo the procedure. If a woman has decided she wants to proceed with amniocentesis, she may want to justify this decision in her mind by indicating that she perceives the risk as lower than a woman who has decided not to undergo the procedure. When decisions are made, individuals often must provide justification for those decisions due to pressures from society, authority, or self (Huber, Bar, \& Huber, 2009). In the case of amniocentesis, a woman may have to provide justification of her decision to herself, her doctor, her family, or her spouse.

Women who stated that they wanted to proceed with amniocentesis because they wanted to know whether or not the pregnancy was affected with a chromosomal problem were significantly more likely to perceive the miscarriage risk associated with amniocentesis as low ( $\mathrm{p}=0.015)$. This finding may be further confirmation that certain aspects of a person's life experiences are used during risk perception and decision-making (Slovic, The Perception of Risk, 2000). Perhaps some women anchor to uncertainty of aneuploidy in the pregnancy and minimize the risk associated with amniocentesis. Further studies are needed to examine how much weight individuals place on certain risks in the decision-making processes.

\section{Changes in Miscarriage Risk Perception}

A large number of participants' view of the risk of amniocentesis remained unchanged after genetic counseling $(60 \% ; n=39)$. Therefore while significantly more participants knew the true numeric risk $(\mathrm{p}<0.0001)$, their perception of the risk remained unchanged. This finding is particularly interesting because it appears that the genetic 
counseling session has little effect on the perception of risk of many patients, even though much of the session is typically focused on a discussion of aneuploidy, amniocentesis, and miscarriage risk. This finding may indicate that many patients' feelings about the miscarriage risk and amniocentesis procedure are rigid before they speak with a counselor, and those discussions with the counselor have little to no influence on their final perception. Perhaps patients use the information that the counselor provides as further "proof" of the acceptability of their decision. For example, if the patient perceives the risk of miscarriage associated with amniocentesis as high and does not feel that they want to proceed with the amniocentesis, they may focus on the possibility of miscarriage due to the procedure during the session as further justification for their perception, whereas those who are more anxious about the possibility of a chromosomal condition may choose to interpret that risk as high and the risk of amniocentesis as low. Ultimately, participants appeared to be anchored to a prior concept regarding the risk (Tversky \& Kahneman, 1974) and the genetic counseling session had minimal effect on this anchor for the majority of patients in this study.

Participants whose risk perception changed after the counseling session were significantly more likely to reduce their risk perception: of those who changed their perception $(n=26), 76.9 \%(n=20)$ lowered their risk perception after counseling $(\mathrm{p}<0.0001)$. Therefore, when the counseling session had an influence on the patient's risk perception, it tended to lower the patient's perception of the risk. Perhaps the risk that is quoted in the genetic counseling session is smaller than the one that the patient is anticipating, which causes the patient's perception to be lower after counseling. Further study is needed to investigate the cause of the lowered risk perception since few factors were found to be associated with change. 
When comparing whether women who changed their risk perception were more likely to be influenced by a certain factor, three factors were found to be statistically significant: whether or not the participant knew someone besides the relationships listed who had a personal history or child with a genetic condition $(\mathrm{n}=5 ; \mathrm{p}=0.036)$, total number of living children ( $\mathrm{p}=0.002)$, and total stillbirths $(\mathrm{n}=2 ; \mathrm{p}<0.0001)$. However, given the small sample sizes it is difficult to determine whether or not these significant factors are true or due to chance.

\section{Strengths and Limitations of the Current Study}

The relatively large and diverse sample set in this study allows for reasonable conclusions to be drawn that are likely applicable to other patient populations around the country. Given that $35.1 \%$ of participants were Caucasian, $26.1 \%$ were Hispanic, and $24.3 \%$ were African American and we were still unable to find significant differences between the racial groups that were anchoring risk perception, it seems that risk perception is individualized by person and not likely due to cultural background. Another strength of the study was the capture of risk perception both pre- and post-counseling. There is limited data regarding change in miscarriage risk perception associated with amniocentesis. This study shows that when risk perception is changed, it tends to be decreased, but that risk perception is unchanged for many seeking genetic counseling.

There were also several limitations of this study. The data was gathered via a selfadministered questionnaire, which caused participants to interpret questions without any guidance. Sixty-six participants left the quantification question blank on the first portion of the survey and 14 left the question blank on the second portion. This may be due to the 
intimidation individuals feel regarding mathematical concepts or because they were afraid of being incorrect. Future studies may wish to explore alternate methods of assessing numeric risk to improve participation. In addition, we did not account for the number of patients who refused to participate in the study; therefore, those who completed the survey may have been motivated to do so and may bias the results of the study. This study was also conducted at multiple satellite clinics in the Houston area, each of which is staffed by different personnel responsible for survey distribution. Lack of consistency of survey distribution may have biased who received the survey and what percentage of the patient population of a given clinic completed the questionnaire.

As women who were counseled with use of an interpreter were excluded, further study may be needed in other populations that may be seen for genetic counseling, such as non-English-speaking patients who may be less familiar with amniocentesis. It would be useful to confirm the results of this study in other populations to determine if the anchoring effects are more homogenous.

\section{Conclusion}

In conclusion, this study aimed to determine how prenatal patients perceived the risk of miscarriage associated with amniocentesis before and after a genetic counseling session. The study also attempted to determine what factors anchor a woman's perception of that risk. In general, most women perceived the risk as low or average pre-counseling and were likely to indicate the risk of amniocentesis as $<1 \%$ risk. A significantly higher percentage of patients correctly identified the numeric risk as $<1 \%$ post-counseling when compared to precounseling $(\mathrm{p}<0.0001)$. However, the study found that the majority of patients' feeling about 
the risk perception did not change after the genetic counseling session $(60 \%)$, regardless of how they perceived the risk before discussing amniocentesis with a genetic counselor. Of those whose perception changed, it was significantly lower post-counseling $(\mathrm{p}<0.0001)$. Few factors were found to influence risk perception in a significant manner. One significant factor was that those with a friend or relative with a personal or family history of a genetic disorder were more likely to perceive the risk as low ( $\mathrm{p}=0.001)$. In addition, having a child already was likely to make a woman perceive the risk as low $(\mathrm{p}=0.038)$. The lack of overall consistent significant factors may reinforce the importance of genetic counseling to elucidate individual concerns. 


\section{Appendix A \\ University of Texas-Health Sciences Center Houston \\ Risk Perception Associated with Amniocentesis}

\section{Amniocentesis Information:}

The purpose of this survey is to understand the thoughts of pregnant women about the risk associated with amniocentesis. An amniocentesis (sometimes called the needle test) is a procedure used to tell if the baby has certain genetic conditions, such as Down syndrome. During an amniocentesis, the doctor uses a needle to remove a few teaspoons of fluid from the water sac.

1. Was this the first time you heard of an amniocentesis?

$\square$ Yes (If yes, proceed to question \#18)
$\square$ No

2. If 1,000 women have an amniocentesis, how many of the 1,000 will have a miscarriage due to the amniocentesis?

out of 1,000 women will have a miscarriage after an

amniocentesis

( if you would prefer, you can provide a percentage:

$\%)$

3. How do you feel about the risk of miscarriage from amniocentesis? It is:

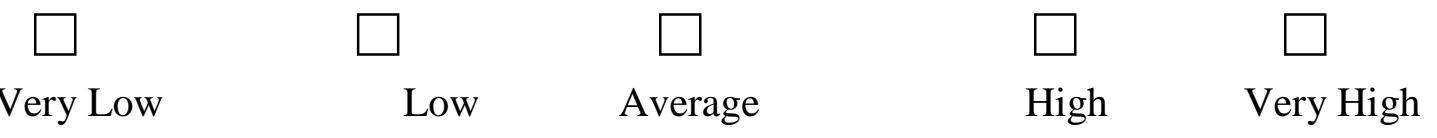

4. Who have you talked to about the amniocentesis? (Check all that apply)

\begin{tabular}{ll}
$\square$ & My doctor \\
$\square$ & My husband/partner \\
$\square$ & My mother \\
& My co-workers \\
$\square$ & No one (Please skip to question $\# 6$ ) \\
\hline$\square$ & My sister \\
\hline & Other:
\end{tabular}

5. If you talked with someone about the amniocentesis, did they suggest that you get the amniocentesis?

$\square$ Yes
$\square$ No
$\square$ They did not give a suggestion 
6. Where have you read information about amniocentesis? (Check all that apply)

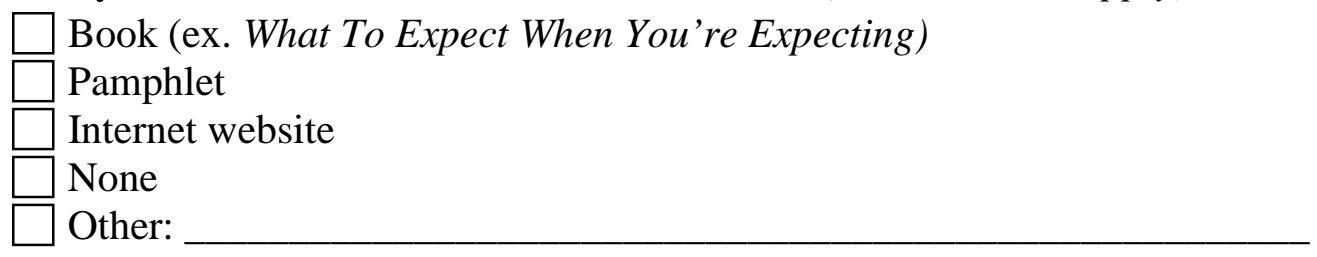

7. Have you ever had an amniocentesis performed in a previous pregnancy? (Check one)

$\square$ Yes

$\square$ No (If no, please skip to question \#11)

$\square$ I don't know

8. If yes, how many times have you had an amniocentesis performed in a previous pregnancy? (Check one)

$\square$ One
$\square$ Two
$\square$ Three or more

9. What did the amniocentesis results show? (Check all that apply)

$\square$ No problem (normal chromosomes)

Down syndrome

Trisomy 18

Trisomy 13

$\square$ Extra or missing sex chromosome problem (such as Turner or Klinefelter syndrome)

$\square$ Neural tube/open spine defect (spina bifida)

I don't know

Other:

10. Did you have any complications after the amniocentesis?

$\square$ Yes (if yes, please check which complications below)

$\square$ Bleeding
$\square$ Fluid Leakage
$\square$ Fever
$\square$ Miscarriage
$\square$ Other:

$\square$ No

11. Do you have friends or relatives who have had the amniocentesis?

$\square$ Yes (if yes, please check who below) 


$\square$ Friend
$\square$ Mother
$\square$ Sister
$\square$ Sister-in-law
$\square$ Another family member
$\square$ Coworker
$\square$ Other:
$\square$ No (If no, please skip to question \#14)
$\square$ I don't know

12. Did the amniocentesis show any problems with their baby?

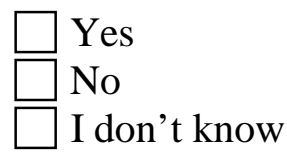

13. Did your friend/relative/coworker have any complications from the amniocentesis?

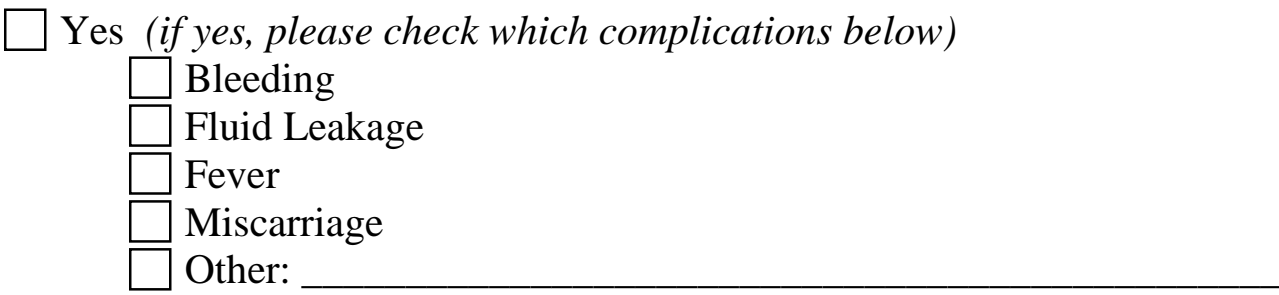
$\square$ No

14. Do you have any friends/relatives/coworkers who have a child or a personal history of a genetic disorder or birth defect?

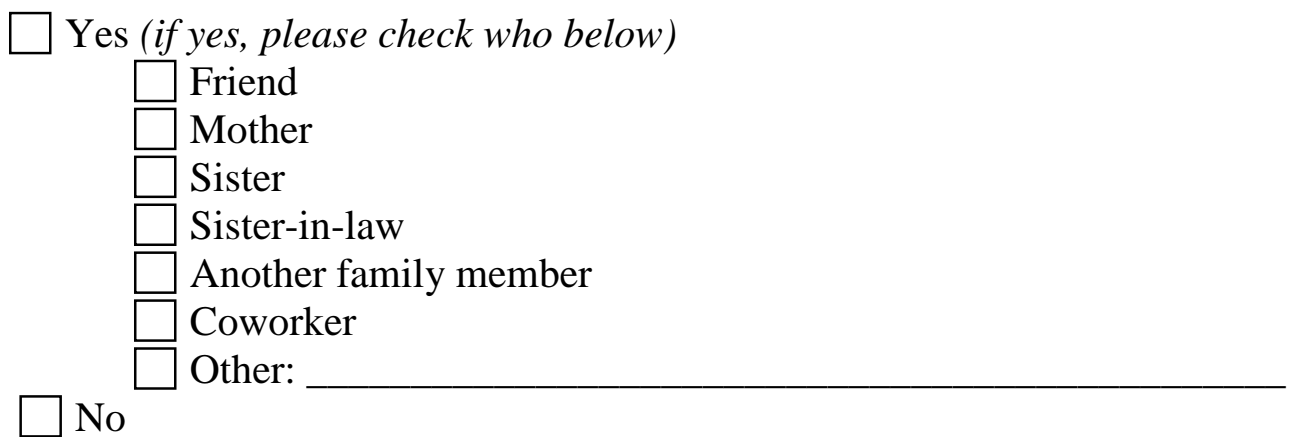

15. What genetic disorder or birth defect does your friend/relative/coworker have?

Please describe:

16. Have you ever had genetic counseling before today?

$\square$ Yes 
If yes, when did you have genetic counseling (year):

If yes, for what reason did you have genetic counseling:

$\square$ Advanced Maternal Age (over 35)

$\square$ Positive blood test for Down syndrome or trisomy 18

$\square$ Positive blood test for open neural tube defect/spina bifida

$\square$ Family history of a genetic condition

Other:

$\square$ No

17. Have any of your children been diagnosed with a genetic disorder or a birth defect (such as cystic fibrosis, sickle cell disease, heart defect, cleft lip, Down syndrome, etc)? (Check one)

$\square$ Yes - please specify the disorder or birth defect:

$\square$ No

$\square$ I don't have any children

\section{Demographics:}

18. How old are you?

years old

19. What is your race/ethnic background? (Check one)

$\square$ African-American

Hispanic

Asian

$\square$ Caucasian

$\square$ Other:

20. What is the highest grade you have completed ?(Check one)

$\square$ Some high school
$\square$ High School
$\square$ Some college
$\square$ College
$\square$ Graduate School

21. What is your total combined annual household income (check one): 


$\square<30,000$
$\square 30,000-60,000$
$\square 60,000-100,000$
$\square>100,000$

22. What is your religious affiliation (Check one)

$\square$ Protestant
$\square$ Catholic
$\square$ Jewish
$\square$ Muslim
$\square$ Buddhist
$\square$ Hindu
$\square$ None
$\square$ Other:




\section{Appendix B \\ University of Texas-Health Sciences Center Houston \\ Risk Perception Associated with Amniocentesis}

During the genetic counseling session, the genetic counselor discussed the amniocentesis with you.

1. If 1000 women have an amniocentesis, how many of the 1000 will have a miscarriage due to the amniocentesis?

out of 1000 women will have a miscarriage after an amniocentesis

(If you would prefer, you can provide a percentage: $\%)$

2. How do you feel about the risk of miscarriage from amniocentesis? It is:

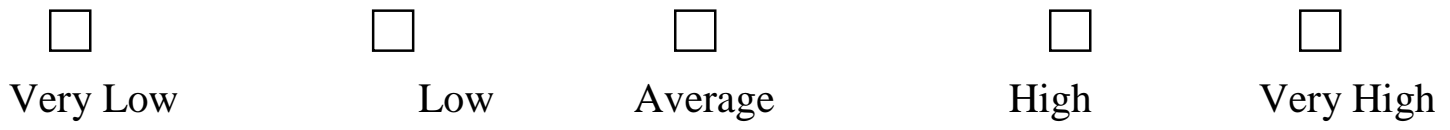

3. Is the amniocentesis is something that you plan to do in this pregnancy?

Yes (if yes, please check all that apply)

$\square$ I need to know if the baby has a genetic condition like Down syndrome before birth

$\square$ I think that the risk associated with amniocentesis was low.

I had one in a previous pregnancy and everything was fine

Other:

$\square$ No (if no, please check all that apply)

The risk of miscarriage is too high

I do not like needles

$\square$ It doesn't matter to me if the baby has a genetic condition like Down syndrome

I had a friend/relative with a problem after amniocentesis

I don't know what the amniocentesis will tell me about the baby

I don't think that my baby has a problem

Other:

Unsure/Not at this visit (if unsure, please check all that apply)

$\square$ I need to speak to my husband/partner

$\square$ I want to wait and see if there are any abnormalities on ultrasound first

$\square$ Other: 


\section{Appendix C \\ University of Texas-Health Sciences Center Houston \\ Influence of Anchoring on Miscarriage Risk Perception Associated with Amniocentesis}

1. Risk of miscarriage from amniocentesis quoted to patient:

$\square 1$ in $200 \quad \square 1$ in $250 \quad \square 1$ in $300 \quad \square 1$ in $500 \quad \square$ other:

2. Which of the following factors (if any) do you feel influenced the patient's decision regarding amniocentesis:

(check all that apply)

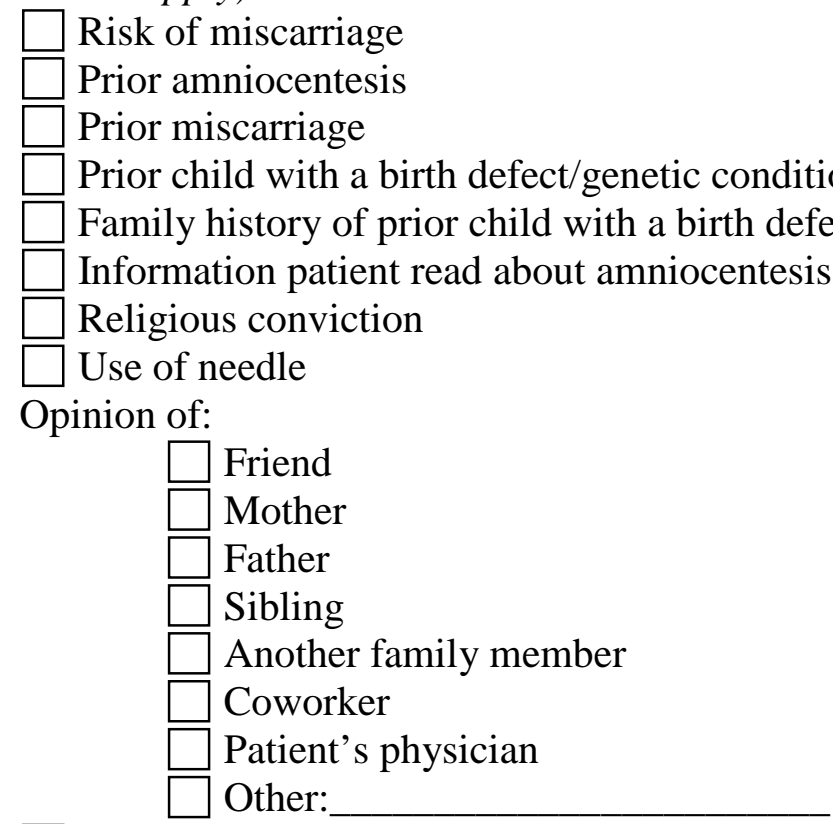

Other:

3. Is the patient having amniocentesis?

Yes (if yes, due to)

$\square$ She expressed a need to know if the baby has a genetic condition before birth

$\square$ She felt that the risk associated with amniocentesis was low.

$\square$ She had an amniocentesis previously

Other:

No (if no, due to)

$\square$ The risk of miscarriage is too high

$\square$ Does not like needles

$\square$ It doesn't matter to the patient if the baby has a chromosome problem like Down syndrome

$\square$ She had a friend/relative with a problem after amniocentesis

$\square$ She did not understand the information about amniocentesis 
$\square$ She did not believe that the baby had a chromosome problem Other:

\section{Unsure/Not at this visit (if unsure, due to)}

$\square$ She needed to speak with her husband/partner

$\square$ She wanted to see if there are any abnormalities on ultrasound first Other:

4. Counselor for the session:

$\square$ Carter

$\square$ Czerwinski

$\square$ Hoskovec

Singletary

Sullivan

$\square$ Wilson

5. Did the genetic counselor perform the majority of the session?

$\square$ Yes

$\square$ No (if no, then who)

$\square$ First year genetic counseling student

$\square$ Second year genetic counseling student

$\square$ Resident

$\square$ Fellow

6. Were there any other factors that you felt influenced the session? If so, please comment: 


\title{
Appendix D \\ University of Texas-Health Science Center Houston Risk Perception Associated with Amniocentesis
}

\begin{abstract}
Dear Potential Study Participant, You are being invited to take part in a research study called Influence of Anchoring on Miscarriage Risk Perception Associated with Amniocentesis. We are interested in what factors affect a woman's perception of the miscarriage risk associated with a test called amniocentesis. The people in charge of this research project are Regina Nuccio and Claire Singletary at the University of Texas Medical School Houston. For this research study, they will be called the Principal Investigators, or PIs.

Your decision to join this research study is voluntary. You may refuse to take part, or choose to stop taking part at any time. Your decision about participation in this study or answering questions will not change the care or services that you receive from the University of Texas Health Science Center Houston.

This research study involves taking an anonymous survey to look at factors that affect what people think about the risk of miscarriage risk associated with amniocentesis. Amniocentesis is a prenatal procedure that involves inserting a needle into a woman's abdomen in order to remove 4 teaspoons of liquid from the sac that the baby floats in. A test is then run on the cells in this liquid that can tell if the baby has a chromosome problem, such as Down syndrome.
\end{abstract}

If you agree to join this study, you will be given the survey in two parts. The first part will be given to you before your genetic counseling session. This part of the survey includes questions about people you may or may not have discussed the amniocentesis with as well as personal, medical, family, and pregnancy history. The second part will be given to you after the genetic counseling session while you are waiting for your ultrasound. This part of the survey is shorter than the first and will ask you some of the same types of questions as the first part. Both parts of the survey will take about 10 minutes to complete. Your responses will be confidential and will be viewed only by the researchers involved in the study. You will not be asked to include your name or any information that will personally identify you. After completing the survey, it will be placed in a sealed envelope for the Principal Investigators. Although the results of this study will be useful for doctors, other health professionals and future pregnant women, there may be no direct benefit to you for participating in this study. There is no physical danger in joining this study. Some of the questions on the survey may make you feel uncomfortable. You can refuse to answer or skip any questions or stop taking the survey at any time. If you decide to participate in the study, it is very important that you answer as honestly as you can to the questions that are asked.

It will not cost you anything to join this study. You will not be paid to complete the survey. All surveys will be kept in a secured area that is only accessible to the research staff. You will not be personally identified in any reports or publications of this study.

If you have any questions or would like more information, please contact Regina Nuccio, BS or Claire Singletary, MS, CGC at (713) 500-5760. If you would like to withdraw from the study at any time, please contact Ms. Nuccio or Ms. Singletary at the above number. If you are willing to take part in our study, please complete and return the survey in the enclosed envelope to the front desk personnel or genetic counselor. 
Thank you very much for considering this invitation to participate in our study. 


\section{REFERENCES}

ACOG Practice Bulletin No. 77: Screening for Fetal Chromosomal Abnormalities. (2007).

Obstetrics \& Gynecology, 109 (1), 217-221.

ACOG Practice Bulletin No. 88: Invasive Prenatal Testing for Aneuploidy. (2007). Obstetrics \& Gynecology, 110 (6), 1459-1467.

Alfirevic, Z., \& Tabor, A. (2007). Pregnancy Loss Rates After Midtrimester Amniocentesis [letter]. Obstetrics and Gynecology, 109 (5), 1203-1204.

Benacerraf, B. (2000). Should sonographic screening for fetal Down syndrome be applied to low risk women? Ultrasound in obstetrics and gynecology, 15 (6), 451-455.

Blessed, W. B., Lacoste, H., \& Welch, R. A. (2001). Obstetrician-gynecologist performing genetic amniocentesis may be misleading themselves and their patients. American Journal of Obstetrics and Gynecology, 184 (7), 1340-1344.

Eddleman, K. A., \& Malone, F. D. (2007). Pregnancy Loss Rates After Midtrimester Amniocentesis [letter]. Obstetrics and Gynecology, 109 (5), 1204.

Eddleman, K. A., Malone, F. D., Sullivan, L., Dukes, K., Berkowitz, R. L., Kharbutli, Y., Porter, T. F., Luthy, D. A., Comstock, C. H., Saade, G. R., Klugman, S., Dugoff, L., Craigo, S. D., Timor-Tritsch, I. E., Carr, S. R., Wolfe, H. M., \& D'Alton, M. E. (2006). Pregnancy Loss Rate After Midtrimester Amniocentesis. Obstetrics and Gynocology, 108 (5), 1067-1072.

Eisenberg, B., \& Wapner, R. J. (2002). Clinical procedures in prenatal diagnosis. Best Practice \& Resarch Clinical Obstetrics and Gynaecology, 16 (5), 611-627.

Fuchs, F., \& Riis, P. (1956). Antenatal Sex Determination. Nature, 177, 330.

Gates, E. A. (2004). Communicating Risk in Prenatal Genetic Testing. American College of NurseMidwives , 49 (3), 220-227. 
Garcia, E., Timmermans, D. R., \& van Leeuman, E. (2008). The impact of ethical beliefs on decisions about prenatal screening tests: Searching for justification. Social Science \& Medicine, 66, 753-764.

Huber, O., Bar, A. S., \& Huber, O. W. (2009). Justification pressure in risky decision making: Search for risk defusing operators. Acta Psychologica, 130, 17-24.

Hunt, L. M., de Voogd, K. B., \& Castendeda, H. (2005). The routine and the traumatic in prenatal genetic diagnosis: does clinical information patient decision-making? Patient Education and Counseling, 302-312.

Kirkham, C., Harris, S., \& Grzybowski, S. (2005). Evidence-Based Prenatal Care: Part I. General Prenatal Care and Counseling Issues. American Family Physicians, 71 (7), 1307-16.

Leschot, N., Verjaal, M., \& Treffers, P. (1985). Risks of midtrimester amniocentesis; assessment in 3000 pregnancies. British Journal of Obstetrics and Gynaecology, 92, 804-807.

Malone, F. D., Canick, J. A., Ball, R. H. , Nyberg, D. A., Comstock, C. H., Bukowski, R., Berkowitz, R. L., Gross, S. J., Dugoff, L., Craigo, S. D., Timor-Tritsch, I. E., Carr, S. R., Wolfe, H. M., Dukes, K., Bianchi, D. W., Rudnicka, A. R., Hackshaw, A.K., LambertMesserlian, G., Wald, N. J., D'Alton, M. E. (2005). First-Trimester or Second-Trimester Screening, or Both, for Down's Syndrome. The New England Journal of Medicine, 353 (19), 2002-2011.

Mujezinovic, F., \& Alefirevic, Z. (2007). Procedure-Related Complications of Amniocentesis and Chorionic Villous Sampling: A Systematic Review. Obstetrics \& Gynecology, 110 (3), 687694.

Niermeijer, M., Sachs, E., Jahodova, M., Tichelaar-Klepper, C., Kleijer, W., \& Galjaard, H. (1976). Prenatal diagnosis of genetic disorders. Journal of Medical Genetics, 13 (3), 182-194. 
Olney, R. S., Moore, C. A., Khoury, M. J., Erickson, J. D., Edmonds, L. D., \& Botto, L. D. (1995, July 21). Chorionic Villus Sampling and Amniocentesis: Recommendations for Prenatal Counseling. CDC: Morbidity and Mortality Weekly Report.

Philip, J., \& Bang, J. (1978). Outcome of pregnancy after amniocentesis for chromosome analysis. British Medical Journal, 2, 1183-1184.

Romero, R., Jeanty, P., Reece, E. A., Grannum, P., Bracken, M., Berkowitz, R., \& Hobbins, John C. (1985). Sonographically Monitored Amniocentesis To Decrease Intraoperative Complications. Obstetrics \& Gynecology, 65 (3), 426-430.

Rotmensch, S., Liberati, M., Bronshtein, M., Schoenfeld-Dimaio, M., Shalev, J., Ben-Rafael, Z., \& Copel, J. A. (1997). Prenatal Sonographic Findings In 187 Fetuses with Down Syndrome. Prenatal Diagnosis, 17 (11), 1001-1009.

Simpson, N. E., Dallaire, L., Miller, J. R., Siminovich, L., Hamerton, J., Miller, J., \& McKeen, C. (1976). Prenatal diagnosis of genetic disease in Canada: report of a collaborative study. Canadian Medical Association Journal, 115, 739-748.

Slovic, P. (2000). The Perception of Risk. In P. Slovic, The Perception of Risk (pp. 220-231). London, England: Earthscan Publication Ltd.

Slovic, P., Fischhoff, B., \& Lichtenstein, S. (2000). Cognitive Processes and Societal Risk Taking. In P. Slovic, The Perception of Risk (pp. 32-50). London, England: Earthscan Publication Ltd.

Slovic, P., Fischhoff, B., \& Lichtenstein, S. (2000). Rating the Risk. In P. Slovic, The Perception of Risk (pp. 104-120). London, England: Earthscan Publications Ltd. 
Stevens, B., Mastrobattista, J., Gambello, M., Swaim, L., King, T., Strassberg, M., \& Singletary, C. N. (2008). Effect Of Miscarriage Risk On Amniocentesis Decision-Making. Unpublished master's thesis, University of Texas--Houston.

Tabor, A., Madsen, M., Obel, E. B., Philip, J., Bang, J., \& Norgaard-Pedersen, B. (1986, June 7). Randomised Controlled Trial of Genetic Amniocentesis in 4606 Low-Risk Women. The Lancet, 1287-1293.

Tversky, A., \& Kahneman, D. (1974). Judgement under Uncertainty: Heuristics and Biases. American Association for the Advancement of Science, 185 (4157), 1124-1131.

Vergani, P., Locatelli, A., Biffi, A., Ciriello, E., Zagarella, A., Pezzullo, J. C., \& Ghidini, A. (2002). Factors affecting the decision regarding amniocentesis in women at genetic risk because of age 35 or older. Prenatal Diagnosis, 22, 769-774.

Woo, J. (2007). A Short History of Amniocentesis, Fetoscopy, and Chorionic Villus Sampling. Retrieved December 13, 2009, from http://www.ob-ultrasound.net/amniocentesis.html 


\section{VITA}

Regina Anne Nuccio was born in Upper Heyford, England on January 9, 1986. She is the daughter of Jeffrey and Katherine Nuccio. After completing her work at Briarcrest Christian High School, in Memphis, Tennessee in 2004, she entered Clemson University in Clemson, South Carolina. She received the degree of Bachelor of Science with a major in Psychology in December of 2007. She entered the University of Texas Genetic Counseling Program in the Fall of 2008 and graduated with a Master of Science in Genetic Counseling in May 2010. 